\title{
Assessing the effectiveness of descriptive and experimental analyses to identify variables influencing problem behavior in domestic dogs
}

Susan D. Kapla

West Virginia University

Follow this and additional works at: https://researchrepository.wvu.edu/etd

\section{Recommended Citation}

Kapla, Susan D., "Assessing the effectiveness of descriptive and experimental analyses to identify variables influencing problem behavior in domestic dogs" (2005). Graduate Theses, Dissertations, and Problem Reports. 2261.

https://researchrepository.wvu.edu/etd/2261

This Dissertation is protected by copyright and/or related rights. It has been brought to you by the The Research Repository @ WVU with permission from the rights-holder(s). You are free to use this Dissertation in any way that is permitted by the copyright and related rights legislation that applies to your use. For other uses you must obtain permission from the rights-holder(s) directly, unless additional rights are indicated by a Creative Commons license in the record and/ or on the work itself. This Dissertation has been accepted for inclusion in WVU Graduate Theses, Dissertations, and Problem Reports collection by an authorized administrator of The Research Repository @ WVU.

For more information, please contact researchrepository@mail.wvu.edu. 
Assessing the Effectiveness of Descriptive and Experimental Analyses to Identify Variables Influencing Problem Behavior in Domestic Dogs

\author{
Susan D. Kapla
}

Dissertation submitted to the Eberly College of Arts and Sciences at West Virginia University

in partial fulfillment of requirements for the degree of

\author{
Doctor of Philosophy \\ in \\ Psychology \\ Cynthia M. Anderson, Ph.D.,Chair \\ Karen G. Anderson, Ph.D. \\ Barry Edelstein, Ph.D. \\ B. Kent Parker, Ph.D. \\ John E.Warren, Ph.D. \\ Department of Psychology \\ Morgantown, West Virginia \\ 2005
}

Keywords: Functional Assessment, Functional Analysis, Dogs, Problem Behavior Copyright 2005 Susan D. Kapla 


\begin{abstract}
Assessing the Effectiveness of Descriptive and Experimental Analyses to Identify Variables Influencing Problem Behavior in Domestic Dogs
\end{abstract}

Susan D. Kapla

Problem behavior in dogs is a concern for pet owners. Many contemporary approaches to intervention first involve a process of diagnosis and classification which is often structural in nature. An accurate diagnosis is considered essential for effective treatment, however, outcome data validating the efficacy of this procedure are dubious. The success of strategies used to assess and treat behavior problems that identify behavioral function in humans (functional assessment), however, suggests the potential utility of such techniques in the assessment and treatment of behavior problems in dogs. Therefore, two separate assessments were conducted to identify and manipulate variables affecting problem behavior in dogs. An initial assessment comprised of indirect and direct observations suggested hypotheses that were tested experimentally in assessment two. In assessment two, the manipulation of environmental events suggested by these hypotheses demonstrated functional relations controlling problem behavior in pet dogs. 


\section{Table of Contents}

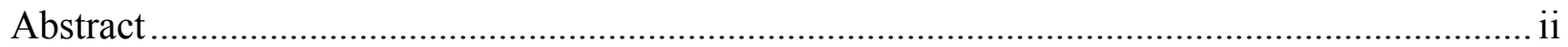

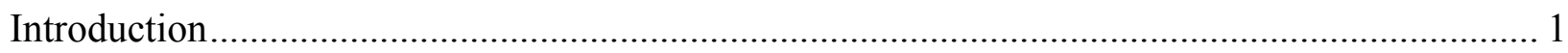

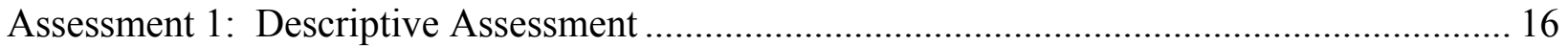

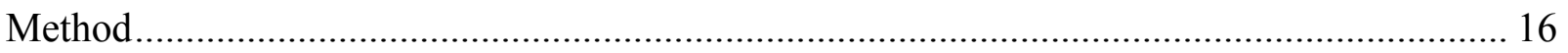

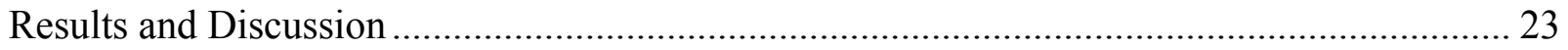

Assessment 2: Contingency Manipulation............................................................................. 28

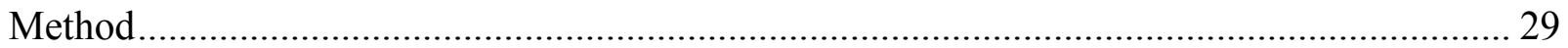

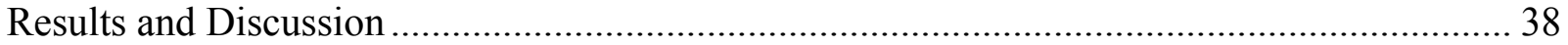

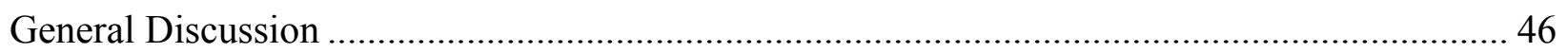

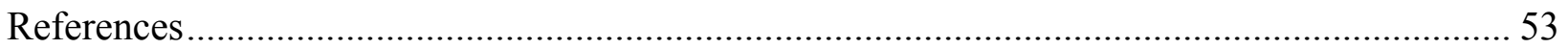

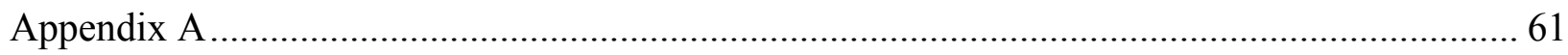

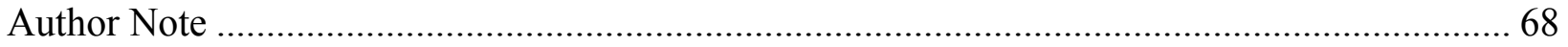

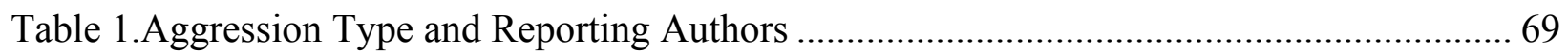

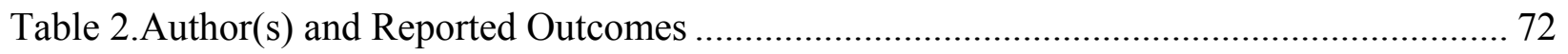

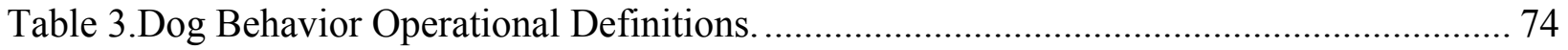

Table 4.Owner Behavior Operational Definitions and Conditions in Which the Event was

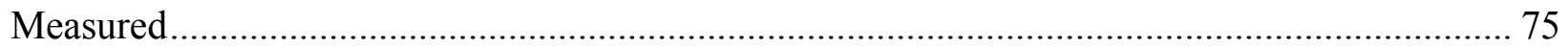

Table 5.Formulas for Calculating Conditional Probabilities .............................................. 76

Table 6.Measures of Interobserver Agreement for Descriptive Assessment............................ 77

Table 7.Measures of Interobserver Agreement for Contingency Manipulation (Assessment 2) . 81

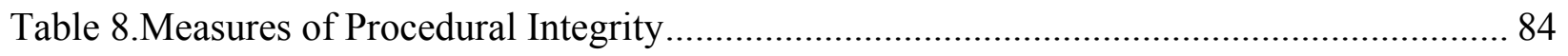

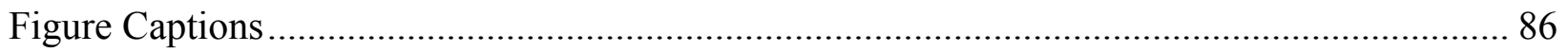


Figure 1. Results of Descriptive Assessment for Elmo. ............................................................. 88

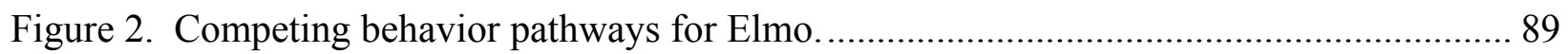

Figure 3. Proportion of intervals with jump or toy-carrying for Iggy during the descriptive

assessment.

Figure 4. Antecedent conditional probabilities for Iggy from the descriptive assessment.......... 91

Figure 5. Consequence conditional probabilities for Iggy from the descriptive assessment........ 92

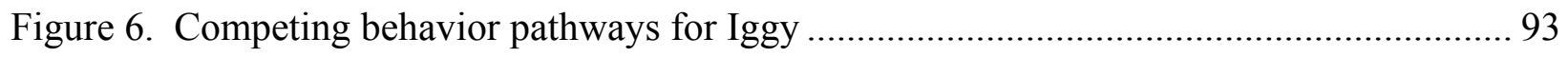

Figure 7. Results from descriptive assessment for Stanley in the hug condition. ....................... 94

Figure 8. Competing behavior pathways for Stanley in the hug condition. ............................... 95

Figure 9. Proportion of intervals with jump and toy-carrying for Stanley in the arrivals condition

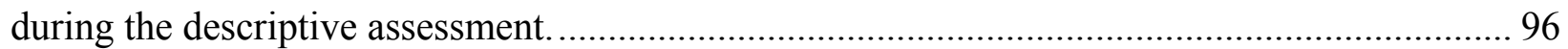

Figure 10. Antecedent conditional probabilities for Stanley in the arrivals condition during the

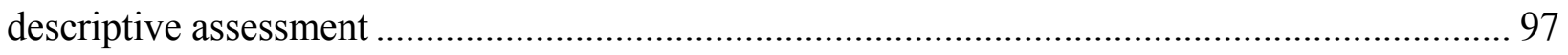
Figure 11. Consequence conditional probabilities for Stanley in the arrivals condition during the

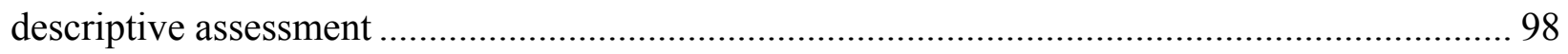

Figure 12. Competing behavior pathways for Stanley in the arrivals condition ........................ 99

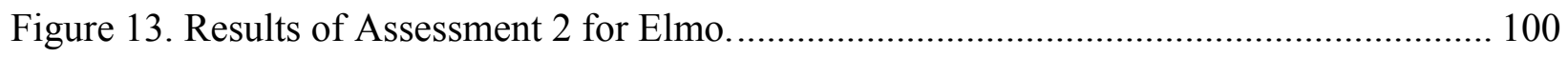

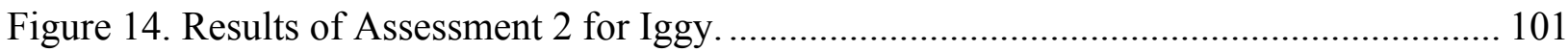

Figure 15. Results of Assessment 2 for Stanley in the hug condition ....................................... 102

Figure 16. Results of Assessment 2 for Stanley in the arrivals condition. ................................ 103 
Assessing the Effectiveness of Descriptive and Experimental Analyses to Identify Variables Influencing Problem Behavior in Domestic Dogs

The assessment and treatment of behavior problems seen in dogs is a growing area of study and interest. Thirty five percent of American homes are shared with at least one dog (Wise \& Yang, 1994), making the domestic dog one of the most popular pets in the United States. However, the dog-human relationship is often far from perfect, and the reported incidence of behavior problems exhibited by domestic dogs seen by veterinarians has been increasing over the past 25 years (Beaver, 1999). Some of the most common problem behaviors in dogs include, but are not limited to, excessive barking, destructive behavior, inappropriate elimination, coprophagia, running away, aggression and stereotypy (Overall, 1997).

Despite the broad range of problem behaviors, the most common behavior problem presented for treatment is aggression (e.g. Houpt, 1985; Knol, 1987; Mugford, 1984; Wright \& Nesselrote, 1987) followed by stimulus reactivity and separation-related problems (Wright \& Nesselrote, 1987). As the most common problem behavior presented for treatment in pet dogs, aggression is often viewed as a priority for practitioners and researchers (Mugford, 1984) and constitutes the topic of much of the research on problem behavior in dogs (e.g., Polsky, 1995).

The first step in the prevailing approach to treatment of problem behavior such as aggression is to diagnose or classify it based on the target (e.g., another dog, a person), behavioral topography, and/or antecedent conditions (such as presence of food, relative proximity to territorial boundaries, etc.). Unfortunately, a standardized classification system for aggression does not exist (Beaver, 1993). Instead, different investigators have developed different classification systems that often are inconsistent (Reisner, 2003). Most current systems include elements of a classification system developed by Moyer in 1968. Moyer's system divided 
aggression into seven types categorized by the hypothesized neural and endocrine basis associated with the respective behavior and the type of stimuli that evoked it. The types included predatory, inter-male, fear-induced, irritable, territorial, maternal and instrumental. Subsequent classification systems have often included more than twice as many categories (see Table1).

Also problematic is that researchers often use different terminology to describe behaviors occurring under similar circumstances [e.g., Overall (1993) referred to aggression that was unpredictable, violent and uncontrolled as idiopathic aggression whereas Beaver (1980) referred to it as mental lapse syndrome; Borchelt \& Voith, (1996) and Borchelt (1983) placed aggression occurring in the presence of food in the possessive category while Beaver (1983) placed it in the dominance category]. Some investigators have also grouped subcategories into more broad categories based on targets such as owner-directed, stranger-directed and animal-directed (Houpt $\&$ Reisner, 1995), or offensive versus defensive (Young, 1988).

It is understandable that many categories would overlap given the breadth of contexts in which aggression occurs and the various behavioral topographies that accompany it. However, there are two primary concerns with this type of categorization. The first is that the category presumably indicates the cause or mechanism, and the second is that an accurate diagnosis or classification is considered critical for effective treatment (Beaver, 1994).

\section{Mechanism and Treatment}

If a dog is diagnosed with dominance aggression because aggression occurs when a human steps over the dog, the diagnosis then also suggests that the mechanism or cause of the behavior is dominance. Treatment might then be focused on changing dominance. This is best summarized by Overall (1997) who states that "a diagnosis is actually a hypothesis to be tested; when we suggest a diagnosis, we are also suggesting or assuming some level of mechanism for 
it" (p. 4). Since many of the diagnostic categories utilize ethological descriptions (such as territoriality or dominance), recommended behavioral interventions often combine elements of environmental change with the purported restructuring of the dog's rank in the social hierarchy. For example, training techniques which prescribe the delivery of differential reinforcement when the dog looks away from the owner are often interpreted as contributing to the elevation of the owner to a leadership position (Grognet \& Parker, 1992) or in reversing the dominance hierarchy (Voith \& Borchelt, 1982). Many descriptions of intervention in the literature include similar blends (e.g., Borchelt \& Voith, 1996; Cameron, 1997; Overall, 1993) despite a lack of evidence supporting the idea that treatment actually changes the social hierarchy (Reisner, 1997). Evidence indicating change in the purported mechanism is difficult if not impossible to gather because the causal mechanism often is either a non-physical entity inside the dog (e.g., temperament) or refers to some ill-defined and difficult to recognize construct, such as "social hierarchy." Given these difficulties, it is troubling that an accurate diagnosis is considered necessary for effective treatment (Overall, 1997).

Treatments are designed to address the presumed mechanism or cause of the behavior derived from a structural or syndromal diagnosis of the problem. The advantages of a structural or syndromal classification system (such as the DSM-IV for psychological disorders in humans) include guidance toward an initial starting point for a functional analysis (Hayes \& Follette, 1992; Scotti, Morris, McNeil \& Hawkins, 1996), assistance in meeting health care insurance requirements, improved communication across disciplines, and some direction regarding common prognosis and intervention (Scotti et al., 1996). However, the treatment utility of such classification has not been demonstrated in the dog problem behavior literature, and in humans has been described as weak (Hayes \& Follette, 1993; Hayes, Nelson \& Jarrett, 1987). Hayes \& 
Follette (1993) point out that similar structural topographies may have differential functions while dissimilar structural topographies may have similar functions, and that syndromal classification diverts the focus from environment-behavior relations to causal mechanisms lying within the client.

With dogs, diagnostic-driven intervention research is weak for several reasons. First, there simply are a very small number of published treatment outcome studies (Borchelt \& Voith, 1996), and intervention efficacy is generally judged via owner report (e.g., Juarbe-Diaz \& Houpt, 1996; Wells, 2001). Second, of existing studies, few specify the link between the diagnosis and the intervention. Third, the treatments that are prescribed for dog problem behavior are often vague and in some cases are simply noted as "behavior modification" (Beaver, 1983) with no description of the specific components, thus rendering it impossible to determine whether the diagnosis was useful in deriving an effective intervention. Often several treatment strategies (e.g. habituation, extinction, desensitization, etc.) are reported (e.g. Overall, 1993) but there is no indication of which is prescribed and when. Also, many authors recommend a similar intervention for all cases of a specific problem behavior. For example, Borchelt \& Voith (1996) recommended habituation and/or counterconditioning as a potential treatment for every type of aggressive diagnosis they listed, and while Reisner (2003) recommended that aggression not be handled in a "cook book" fashion, she also recommended a standard protocol consisting of sit/stay, sit or down before receiving treats, etc. for all types of aggression regardless of the diagnosis. If "a diagnosis is actually a hypothesis to be tested. .." (Overall, 1997, p. 4), then it seems peculiar to recommend similar treatments for all diagnoses. Table 2 presents a summary of several studies for which treatment outcomes for aggression were reported. With the exception of Tortora (1983) and Williams and Borchelt (2003) who list outcome by treatment 
type, it is not clear which elements of most treatment programs were effective or even necessary.

Structural classification schemes, as described above, base diagnoses on the specific topography of a behavior. Structural descriptions are very useful for describing what the particular behavior looks like. For example, such a description is useful to describe the form of aggression exhibited by a specific dog when a human steps over the dog. However, one problem with making intervention decisions based on the structure of observed responses is that topographically similar responses may be functionally dissimilar (as noted by Hayes \& Follette, 1993 above). For instance, one dog's licking may be maintained by escape or avoidance of human interactions, while another dog's licking may be maintained by human attention. Presumably, the most effective intervention would address the respective function rather than the application of a standardized treatment package. Indeed, research with humans suggests clearly that interventions matched to the function of the target response are more effective than interventions that are contraindicated based on the function (e.g., .Iwata, Pace, Cowdery \& Miltenberger, 1994; Northrup, et al., 1991; Taylor \& Miller, 1997). For instance Iwata et al. (1994) found that extinction was effective in reducing self-injurious behavior in children only when it involved removing the specific reinforcer that had been maintaining the behavior. Taylor \& Miller (1997) demonstrated that a timeout procedure contingent on problem behavior was effective only when the problem behavior was maintained by attention. For two students whose problem behavior was maintained by escape, the timeout procedure worsened problem behavior. Both of these studies clearly demonstrate the importance of basing intervention on the function of the behavior rather than the structure.

Functional Diagnostic Systems 
An alternative to structural diagnosis is functional diagnosis; diagnosis based on the environmental variables that evoke and maintain the target response (Hayes \& Follett, 1993). Some investigators of problem dog behavior do suggest that functional classification schemes are more useful than systems based strictly on the target or a description of the behavior (e.g., Borchelt \& Voith, 1996; Overall, 1997; Reisner, 2003). In the behavioral literature, "function" refers to a change in the dependent variable (the response) as a result of a change in the independent variable (environmental events, Skinner, 1953) and requires a description, not just of antecedent variables that precede the target response (e.g., Borchelt \& Voith, 1996) but also the consequent events that follow and maintain the response. For example a dog in a yard that barks at passersby could be said to be "protecting his/her territory" but a behavioral description of the environment-behavior relation would describe the barking as function of the antecedents or occasion (passersby approaching within a specific distance of the dog who is in his/her yard) that reliably precedes barking and the consequences (the passersby continue walking and increase the distance between the dog and themselves; owners come into the yard and talk to the dog) that typically follow the response. The utility of identifying the function of problem behavior as a relation between variables such as antecedent events, the target response, and its consequences is that such an identification can lead directly to strategies that may alter behavior by altering the antecedent and/or consequent events. When viewed this way, behavior is a product of environmental contingencies that may be altered.

Functional Assessment. Given that treatment of problem behavior based on diagnosis involves the modification of environmental events it seems logical to focus pre-intervention assessment on the specific variables of which the behavior is a function. Viewed this way, the emphasis is on the environment-behavior relation rather than on what may be going on inside the 
organism or the specific topography of the behavior. This approach, functional assessment, has been extensively developed and researched by behavior analysts (e.g., Carr, 1977; Iwata, Dorsey, Slifer, Bauman and Richman, 1982/1994; Neef, 1994; O’Neill, Horner, Albin, Sprague, Storey \& Newton, 1997; Skinner, 1953).

Although two terms, functional analysis and functional assessment are used in the literature, "functional analysis" typically is reserved for the systematic manipulation of antecedent and consequent variables (e.g., Iwata, et al., 1982/1994) resulting in demonstration of a functional relation between a response and environmental events. The term "functional assessment" includes functional analysis as well as other methods of assessment (e.g., unstructured observation, interviews) that assist in developing hypotheses about functional relations but do not demonstrate causal relations. Perhaps one of the most valuable uses of functional analysis is the identification of the events that maintain the problem behavior prior to implementing intervention (Iwata et al., 1982/1994). Pre-treatment functional analysis may assist in eliminating attempts at intervention that may be ineffective, or worse, that could increase the rate of problem behavior. Indeed, the use of pretreatment functional analysis appears to be correlated with the type of treatment chosen by experimenters. Pelios, Morren, Tesch \& Axelrod (1999) found that since the introduction of pretreatment functional analysis, the use of punishment has been decreasing. This would be good news for dogs in an age where reinforcement-based intervention programs for modifying dog behavior are in their infancy (e.g. Burch \& Bailey, 1999; Miller \& Donaldson, 2001; Pryor, 1999).

Functional assessment takes two primary forms, indirect and direct. Indirect assessment techniques, such as interviews and questionnaires, gather information via an informant, and are a common means of gathering information and developing hypotheses regarding problem behavior 
(e.g. O’Neill, et al., 1997). The advantages of indirect assessment methods that make them appealing were summarized by Iwata, Kahng, Wallace and Lindberg (2000). They are often easy to administer (in some cases they can be conducted over the telephone), can be used to obtain a lot of information in a short period of time, and may indicate areas for closer examination. Despite these many advantages, there are several disadvantages associated with indirect assessment. Because interviews and questionnaires rely on caretaker or owner report they can be unreliable and may lack validity. Caretakers/owners must be skilled at observing the behavior's frequency, have good recall and be able to estimate the behavior's probable relation with antecedents and consequences. Caretakers or owners may also be unaware that the behavior and its controlling variables may change over time.

In direct assessment measures, the individual's behavior is actually observed and recorded as it occurs. Environmental events that precede and follow the response are recorded as well. When direct assessment is strictly descriptive, the problem behavior is usually observed in the natural environment with no environmental manipulation on part of the investigator. Often descriptive assessments are conducted directly by caregivers, teachers or other staff who have direct access to the observation of a client's problem behaviors. Because environmental events are not manipulated systematically, descriptive assessment measures do not allow one to make causal statements about the function of the behavior (Anderson \& Long, 2002; Lerman \& Iwata, 1993). As with indirect assessment, direct descriptive assessment techniques have particular strengths and weaknesses. Conducting a descriptive assessment requires skilled observers who must decide what events are important and worth recording. It is also possible that the target behavior will not occur as many owners/caretakers may avoid the conditions that occasion problem behavior. Still, descriptive assessment may be quite useful for identifying idiosyncratic 
events (Carr, Yarbrough \& Langdon, 1997; Mace \& Lalli, 1991) that are related to problem behavior, such as a specific type of request or type of attention. Similarly, descriptive assessments allow one to gather information about the putative schedule of reinforcement for problem behavior. An additional problem with some direct observation methods, especially those that do not predetermine the specific environmental events to be observed and recorded (e.g. attention deprivation or attention delivery) is that observers generally only record events that occur in conjunction with targeted problem behaviors, hence, events that are not temporally contiguous with target behaviors are not recorded. For example, the Functional Assessment Observation (FAO) form developed by O'Neill et al. (1997) allows for the recording of target responses and environmental events that precede or follow problem behavior (the observer determines the temporal relation) to evaluate the extent to which problem behavior is associated with a particular event. From these recordings, problem-based conditional probabilities may be calculated. Such calculations allow for a determination of the proportion of recorded target responses that followed a particular antecedent and the proportion of recorded target responses that were followed by a particular consequence. For example, if aggression occurred 15 times, 14 of which were preceded by requests to move off the couch, then conditional probabilities would reveal that $93 \%$ of the aggression observed occurred in the presence of such requests. One might be tempted to suggest that requests to move evoked aggression. However, such a recording system does not allow for the evaluation of the base rates of the occurrence of environmental events (i.e. how often events occur regardless of the occurrence of a target response). Continuing with the above example, if requests to move were scored a total of 90 times, only 14 of which were followed by problem behavior, conditional probabilities would reveal that only $15 \%$ of all the requests to move preceded problem behavior, suggesting that such requests, in and of 
themselves, likely are not evoking problem behavior. A recording system that can allow for the calculation of these additional probabilities requires a more sophisticated and complex approach that also can be conducted via paper and pencil but which can be facilitated by computerized coding software. However, the trade-off is that this sophisticated approach often requires more highly skilled observers, a higher level of training and, hence, a larger time commitment than may be available to clinical practitioners, parents, or owners.

One of the purposes of conducting functional assessments of any type is to develop hypotheses about functional relations that may lead to development of an efficacious intervention, therefore, it is critical that the behavior and events of interest actually occur. As mentioned prior, owners/caretakers that are experiencing problem behaviors exhibited by their pets or children, sometimes of high severity, may have simply become quite good at avoiding antecedent conditions that may occasion problem behavior. A method that requires systematic manipulation of antecedent variables has been developed to address this potential problem (Anderson \& Long, 2002). In the structured descriptive assessment (SDA), antecedent conditions that are suspected to occasion problem behavior are manipulated in the natural environment while consequences are not. Like other descriptive assessments, the SDA can be conducted in the natural environment and can be conducted by caretakers. Because the antecedent conditions are predetermined, an analysis of environment-behavior relations can be assessed via conditional probabilities and can reveal any correlation between the two. The utility of the SDA for developing efficacious interventions has been demonstrated with children with disabilities (e.g., Anderson \& Long, 2002; English, 2004) and typically developing children (Anderson \& English in press). 
The last broad category of assessments is experimental functional analysis (e.g., the analog functional analysis; Iwata et al., 1982/1994) mentioned above. The analog functional analysis technique involves the direct manipulation of both antecedent and consequences. While usually conducted in a controlled environment such as the laboratory or clinic, the technique has also been found effective in more natural settings such as classrooms (Dunlap et al., 1993; Sasso et al., 1992) and homes (Carr, Hatfield, Austin \& Bailey, 1998; Mace \& Lalli, 1991). This technique allows for the assessment of causal relations by using an experimental design and systematic manipulation of variables hypothesized to be maintaining problem behavior. For instance, conditions that may occasion problem behavior (e.g. attention deprivation) may be systematically manipulated while arranging for the delivery of a programmed stimulus contingent on problem behavior (e.g. attention for inappropriate behavior). While the analog functional analysis is considered "the hallmark of contemporary approaches to behavioral assessment” (Hanley, Iwata \& McCord, 2003, p. 147), the limitations of the analog functional analysis have been outlined by Iwata et al. (2000) and include the relatively large length of time necessary to conduct it, the relatively high skill level required of the investigators, the risk of increasing problem behavior, and the difficulty in assessing low-frequency problem behavior.

Further, and as suggested by Carr et al. (1997), because the analog functional analysis manipulates only specific and rather generic environmental events, the environmental events functionally related to problem behavior in the natural setting may not be identified. Direct observations to identify functionally related events may, therefore, be valuable. While one of the advantages of observing problem behavior as it occurs in the natural environment is the potential identification of functionally related idiosyncratic events (e.g. Carr, et al., 1997; Mace \& Lalli, 1991) such observations may also increase the ecological validity of treatments that are designed 
to be implemented in the natural environment. English (2004), working with four children with disabilities exhibiting severe challenging behavior (e.g., aggression, self-injury), found that function-based interventions derived from observations of behavior in home environments (via the SDA) were more effective in reducing problem behavior than interventions derived from laboratory-conducted analog functional analyses, even when those analyses were conducted by caregivers.

Assessing Problem Behavior in Dogs. The functional assessment of problem behavior in dogs has not been systematically developed to the extent it has with human populations. However, the widespread interest in and use of functional assessment in assessing problem behavior in the human population suggests the potential for extending and evaluating the utility of such techniques in the assessment of problem behavior in dogs. An examination of the assessment strategies that have been used in the assessment of dog problem behavior reveals that semblances of some type of informal and incomplete functional assessment has been reportedly used in most studies. For example, indirect assessment is a common means of gathering information about dog behavior problems usually in the form of a behavioral history questionnaire/interview (Appleby, Bradshaw \& Casey, 2002; Borchelt, 1983; Cameron, 1997; Knol, 1987; Lindsay, 2001; Line \& Voith, 1986; Overall, 1997; Sherman, Reisner, Taliaferro, \& Houpt, 1996; Tortora, 1983; Voith \& Borchelt, 1982, 1996; Young, 1982; 1988). Such assessments collect information indirectly from owners about specific environmental stimuli (eliciting and reinforcing) associated with the target response, sequences of behavior, the history of the problem, and the medical history of the dog.

The importance of directly observing problem dog behavior has also been noted (e.g. Tortora, 1980, 1983; Young, 1988). Often such observations include the manipulation of 
antecedent conditions hypothesized to evoke problem behavior in home and clinical environments, thus resembling the SDA described above. For example, Borchelt \& Voith (1996) provide a set of exercises to be conducted by the clinician and/or owner to determine whether or not the exercise evokes dominance aggression (e.g. stare at the dog, hold muzzle, push dog over, grasp dog's cheek, etc.). The assessment is terminated at the first sign of aggression. Overall (1997) also provides descriptions of behaviors that when observed or when reported as occurring together designate a particular type or category of behavioral pathology. For example, Overall describes territorial aggression as "aggression that is consistently demonstrated in the vicinity of a mobile [e.g., car] or stationary [e.g., yard] circumscribed area when that area is approached by another individual in the absence of an actual, contextual threat from that individual." (p. 519).

While direct observations of problem dog behavior to facilitate classification and diagnosis (and hence intervention) are often suggested as necessary, there have been few published studies reporting empirical data collected from such observations. Much of what has been reported has taken the form of written descriptions of case studies that include multi-component treatments (Lindsay, 2001). One notable exception is a series of case studies reported by Tortora (1980) in a textbook chapter designed to introduce the concept of applied animal psychology. Given the clinical nature of these cases, an experimental design that would demonstrate functional control by both antecedents and consequences was not used, however, these studies are noteworthy in that the author reported the specific variables he manipulated and the data he collected.

The first case included a Dachshund's refusal to enter elevators. The author systematically manipulated and recorded time of day, height discrepancy between the elevator and the floor, and opaque versus transparent covers over the threshold. Data on the frequency of balking (refusal) were depicted from the baseline phase (where the behavior was measured at various 
times of day and showed no differential effect) and from a treatment phase in which a fading procedure of the height discrepancy resulted in complete suppression of balking. In a second case involving a Yorkshire Terrier exhibiting predatory aggression, Tortora recorded and reported the probability of stalking as a function of various potentially eliciting stimuli identified through direct observation (e.g. doorbell, telephone, non-ringing noises). The various antecedents were presented and consequences were recorded; stalking was hypothesized to be occasioned by ringing noises and family commotion and maintained by contingent food delivery. After various interventions including both classical and operant extinction (resulting in slight decrease), timeout plus differential reinforcement of non-stalking behavior (DRO) (slight decrease), and hitting the dog with a newspaper contingent on stalking (slight increase), the rate of problem behavior was reduced by a combination of DRO and counter-conditioning. Although the descriptive assessment suggested that stalking was occasioned by particular noises and activity (i.e. ringing and family commotion) and maintained by food delivered contingent on stalking, the assessment did not systematically manipulate consequences and, therefore, this functional relation could only be inferred. In another paper, Tortora (1983) identified 36 dogs exhibiting defensive (avoidance-motivated) aggression and designed an intervention which included escape from shock contingent on appropriate behavior. The avoidance function of the behavior was hypothesized from descriptive assessments and in all 36 cases the provision of punishment for aggression and escape for appropriate behavior was highly successful. However, because the escape/avoidance function of the behavior was determined from descriptive assessment, this function can only be hypothesized and a functional or causal relation cannot be confirmed. Also, it is impossible to infer function from the successful intervention since the intervention included a series of manipulations including the discrete training of incompatible 
responses, play conditioning, escape conditioning from leash pressure and shock, avoidance conditioning, etc.

\section{Statement of the Problem}

Functional assessment of dog problem behavior is in its infancy. Currently no strategies exist for the systematic assessment of problem behavior in dogs as function of environmental antecedents and consequences. Rather, the emphasis has been on using indirect (e.g. interviews) and direct observation to inform structural classification and diagnosis (Young, 1988) and treatment outcomes assessed via client report. To date, the treatment outcome literature on dog problem behavior is sparse; however, research conducted with humans suggests that the utility of interventions matched to a structural (rather than functional) diagnosis are questionable (e.g., Hayes \& Follette, 1993; Hayes, et al., 1987). Conversely, the advantage of identifying the specific environmental events evoking and maintaining problem behavior (i.e. functional relations) to inform effective treatment has been demonstrated in human populations (Repp, Felce \& Barton, 1988) and suggests the utility of such an approach in the assessment and treatment of dog behavior problems.

The purpose of this study is to demonstrate the use of systematic descriptive and experimental analyses to identify controlling environment-behavior relations that could potentially be used in the development of function-based interventions to reduce or eliminate problem behavior in dogs. As it is a natural and logical progression to proceed from indirect to descriptive to experimental analyses in the creation of a comprehensive assessment and treatment plan for problem behavior (e.g. Dunlap, et al., 1993) two separate assessments were conducted. The first assessment systematically assessed problem behavior and environmental events to develop hypotheses regarding the variables maintaining problem behavior using indirect and 
descriptive assessment methods. A computer-based data recording technique was used which allowed for the coding of all occurrences of problem behavior and environmental events and the calculation of both event-based and problem-based conditional probabilities. The second assessment was an experimental manipulation to test the hypotheses derived from the first assessment.

\section{Assessment 1: Descriptive Assessment}

A descriptive assessment was used to systematically evaluate the relation between problem behavior and environmental events. The purpose of this phase was to develop hypotheses regarding the variables maintaining problem behavior so that those variables could be tested in Assessment 2.

\section{Method}

\section{Participants and Setting}

Three dogs and their owners participated. All dogs were healthy and had been seen by a veterinarian within the past year to preclude health problems as potential causes of problem behavior. Elmo was an 8-year-old neutered male German Shepherd Dog who was referred by his 38-year-old male and 38-year-old female owners for barking. Both of Elmo's owners were graduate students; Elmo's female owner was a graduate student in the Behavior Analysis program in the department of Psychology. Elmo was owned by this couple since the age of eight weeks and shared his home with a female 12-year-old spayed female German Shepherd Dog. Iggy was a 6-year-old neutered male German Shorthaired Pointer X Pit Bull Terrier mix who was referred by his 28-year-old female and 25-year-old male owners for jumping on visitors. Both of Iggy's owners were also students; Iggy's female owner was also a graduate student in the Behavior Analysis program in the department of Psychology. Iggy was owned by these 
owners since the age of 16 weeks; Iggy shared his home with a bird but no other dogs. Stanley was a 4-year-old neutered male Viszla who was referred by his 36-year-old male and 37-year-old female owners for jumping on owners and barking. Stanley's female owner was a professor of Behavior Analysis in the department of Psychology. Stanley was owned by this couple since the age of 11 weeks; Stanley shared his home with a 3-year-old spayed female Beagle and a 5-yearold spayed female Viszla. All descriptive assessments took place in the dog's home setting in which the target behavior occurred.

\section{Behavioral Definitions and Interobserver Agreement}

Descriptive Assessment. Dog problem (target) and non-problem behaviors were individually defined for each dog based on owner report during the interview and from observation of video clips prior to the start of the experiment. The target behaviors identified are listed and defined in Table 3 along with the specific $\operatorname{dog}(\mathrm{s})$ for which the behavior was measured. These behaviors included jump (Stanley and Iggy); bark (Stanley and Elmo); nudge (Elmo and Stanley); mouth (Stanley); and paw (Iggy). Non-problem target behaviors included interactions with a toy and compliance (Stanley and Iggy). Barking for Elmo was scored using continuous frequency recording. All other behaviors were scored using partial-interval recording across consecutive 5 s intervals.

Owner or visitor behaviors also were recorded and are listed and defined in Table 4. All owner/visitor behaviors were coded using a partial interval data collection system across consecutive $5 \mathrm{~s}$ intervals. All sessions were videotaped for later coding by trained observers using Noldus Observer computer coding software.

Interobserver Agreement. Observers were trained undergraduate students from the Psychology department. Prior to beginning coding, observers reviewed flash cards of target 
responses, operational definitions, and key codes. Flash card review continued until the observer was able to identify the definition given the response name, the key code given the response name, and the response name given the key code within $2 \mathrm{~s}$ of card presentation at a minimum rate of 30 correct responses per min and no more than 3 incorrect responses per min. After completion of flash card training, direct observation training commenced using pre-recorded videotaped segments of dog-owner interactions. Observers were required to achieve a minimum of $80 \%$ agreement with a trained observer on all responses and events on three consecutive sessions before proceeding.

Interobserver agreement for target behaviors and events was calculated on $56 \%$ of sessions. For data recorded using partial-interval measures, agreement between the two observers was calculated to obtain agreement percentages for occurrence, non-occurrence and total agreement. For occurrence agreement, the number of agreements of occurrences in each 5-s interval were divided by the number of agreements plus disagreements of occurrences and the ratio was multiplied by 100 to achieve an occurrence agreement percentage. For non-occurrences, the number of agreements of non-occurrences in each 5-s interval were divided by the number of agreements plus disagreements of non-occurrences and the ratio was multiplied by 100 to achieve a non-occurrence agreement percentage. Total agreement was calculated by dividing the overall number of agreements (that the response did or did not occur) by the sum of the agreements plus disagreements and multiplying by 100 to obtain an overall agreement percentage. For frequency measures (barking for Elmo) each session was divided into 5-s intervals and the smaller number recorded by one observer was divided by the larger number recorded by the second observer. The ratio of each interval was then averaged over all intervals and multiplied by 100 . 
Mean occurrence, nonoccurrence and overall agreement scores for target behaviors and owner/visitor behaviors were computed for each dog and are included in Table 6. The mean interobserver agreement across all participants was 98\% (range 96-100\%) for jump, 100\% for nudge, $98.5 \%$ (range $97-100 \%$ ) for bark, 99\% (range $96-100 \%$ ) for paw, $100 \%$ for mouth, 100\% for compliance, $97 \%$ (range 96-100\%) for toy, 95\% (range 92-97\%) for verbal attention, 97\% (range $92-100 \%$ ) for physical attention, $100 \%$ for contact, $100 \%$ for part, $100 \%$ for hind scratch, $100 \%$ for prompt, $95 \%$ (range $92-97 \%$ ) for attends to other, and 100\% for tangible delivery. The total agreement coefficient for barking measured as continuous frequency (Elmo) was 98\% (98$98 \%)$.

\section{Design and Procedure}

Indirect assessment (interview). A modified version of the Functional Analysis Interview (FAI) form developed by O'Neill et al. (1997) was used. The form was modified to address issues specific to dog problem behavior (see Appendix A). Several of the questions came from a Dog Behavioral History form used by the University of Georgia’s College of Veterinary Medicine Behavior Service (1999); others were original. The interview with the primary owner/caretaker was conducted by the investigator in person or by telephone. Information regarding the dog's behavioral and medical history was collected and used in the development of response definitions, the identification of potentially relevant antecedent or consequent events, and times of day when problem behaviors was most likely to occur. This information was entered into a behavior pathway chart (following recommendations of O’Neill et al., 1997) for each dog to facilitate the development of hypotheses for use in Assessment 2.

Descriptive assessment. Each dog was observed in the context hypothesized to occasion problem behavior, based on the FAI. The descriptive assessment was modeled after the SDA 
(Anderson \& Long, 2002). Therefore, antecedent events hypothesized to precede problem behavior were systematically presented but consequent events were not predetermined. Instead, owners were instructed to respond to their dog as they typically did, as if they were not being observed. Only one antecedent event was manipulated per condition, and the number of conditions conducted per dog was dependent on the number of hypothesized antecedent events. For Elmo and Iggy, only one setting event was identified for each dog (visitors arriving and owners hugging, respectively) and only one condition was conducted for each dog. For Stanley, because the interview suggested that owner hugging and owners arriving home preceded problem behavior, two separate conditions were conducted, an owners hugging and an arrivals condition.

At least three sessions were conducted per condition and were continued until stability was observed (judged via visual inspection by two independent observers). Session length for hugging (Stanley and Elmo) was determined by the amount of time necessary for owners to hug three to four times (approximately $2.5 \mathrm{~min}$ ). Session length for Stanley arrivals was five minutes, and session length for Iggy visitor arriving was two minutes. The number of observation sessions per day varied depending on the target responses and contexts in which the behavior occurred. For Iggy, one to two sessions with an intersession interval of 5-10 min were conducted each day when visitors were expected to arrive. For arrival sessions with both Stanley and Elmo, one session per day was conducted. For Stanley hugging, one to two sessions were conducted each day with at least a 30-min intersession interval.

The results of the FAI with Elmo's owners resulted in identification of one antecedent condition for barking, the owners hugging in any part of their home. Thus, to establish hugging as an antecedent condition, the descriptive assessment arranged for owners to hug in the living 
room of their home. The owners began each session with a hug and were told to respond to the dog as they normally would. After each hug the owners sat down, pretended to read, watch television or whatever they would normally do. Toys were not provided nor made available to Elmo since owners did not report toys being a relevant variable.

Iggy's owners reported that his jumping occurred when visitors arrived in their home and either sat or knelt and interacted with Iggy. Thus, to establish visitors arriving as a setting event, four individuals (one male and three females) were enlisted to arrive at the owners' home and enter the house individually. Each individual was familiar to Iggy. Visitors were told to interact with Iggy as they normally would. Toys and chew items were freely available.

The FAI conducted with Stanley revealed two antecedent conditions for problem behavior, owner hugging for barking, and arriving home as an antecedent for jumping. The hugging condition was conducted as described for Elmo however toys were freely available as Stanley's owner indicated that toys were always present in the house. With regard to the arrival condition, a dog door allowed access to both the yard and house while owners were away. Jumping reportedly occurred as soon as the arriving owners entered the yard gate and would continue while the owners entered the house, sat down to check mail, etc. Therefore, to establish owners arriving as a setting event, the assessment arranged for owners to arrive home, open the yard gate, proceed to the house, enter the house and sit to check mail. Since three dogs (including Stanley) lived in the owner's home, owners were instructed to respond to each of the dogs as they normally would. Toys and chew items were freely available.

\section{Data Analysis.}

The videotaped sessions from the descriptive assessment sessions were coded using the Noldus Observer. This program allowed for real time coding of all targeted responses and 
environmental events. Both behavior-based and event-based probabilities were calculated to determine the relation between target behavior and environmental events. Behavior-based probabilities indicate the proportion of time a given problem behavior preceded or followed a particular event. For instance, such probabilities answer the questions: Of all recorded instances of problem behavior, how often does problem behavior follow a particular antecedent? How often is problem behavior followed by a particular consequence? Behavior-based probabilities were calculated as indicated in Table 5. Event-based probabilities indicate the proportion of times that a given event either preceded or succeeded problem behavior and were calculated as indicated in Table 5. By including event-based probabilities, one can evaluate base rates of the occurrence of events or the extent to which events occurred irrespective of problem behavior.

Proportions were calculated for environmental events that preceded or followed problem behavior by $5 \mathrm{~s}$ or less. Because one variable-hugging — occurred continuously for some period of time, conditional probabilities were calculated for all problem behavior and environmental events that occurred while hugging was ongoing and within $5 \mathrm{~s}$ after hugging terminated. In addition, if multiple responses occurred in succession, events preceding and succeeding the behavior were only counted once. For instance, if verbal attention (1) occurred, followed by a jump (1), followed by verbal attention (2) and then jump (2), then verbal attention (1) was counted as an antecedent event for jump (1) but verbal attention (2) was counted only as a consequence for jump (1).

Probabilities for consequence events were calculated for all dogs. Because the antecedent stimulus evoking problem behavior in the hugging condition (i.e., hugging) was clear, antecedent proportions were not calculated for this condition with either Stanley or Elmo. However, the specific antecedent conditions evoking problem behavior in the arrivals condition were less 
obvious, as neither Iggy nor Stanley exhibited jumping continuously throughout entire sessions. Thus, for these dogs, a variety of stimuli were analyzed using antecedent conditional probabilities. The antecedent and consequence events evaluated included: verbal attention, physical attention, hind scratch, attention to other dog, prompt, tangible delivery, part, and contact. See Table 4 for the specific definition of the events and for which $\operatorname{dog}(\mathrm{s})$ they were coded.

\section{Results and Discussion}

Results of the descriptive assessments and behavior pathways (developed via the modified FAI and from the descriptive assessment) and are depicted in Figures 1-12. Elmo

Results of the descriptive assessment for Elmo are depicted in Figure 1. Figure 1 (top panel) depicts the frequency of barks occurring during the first $40 \mathrm{~s}$ of hugging (due to experimenter error, session four lasted for only $18 \mathrm{~s}$ ). Although somewhat variable, barking occurred at high rates across sessions.

The middle panel of Figure 1 depicts behavior-based conditional probabilities for Elmo during the descriptive assessment, which took place when owners were hugging. These data indicate the proportion of barks that were followed by each particular event (verbal attention, physical attention and part). In other words, these data answer the question, "of all the times that barking occurred, what proportion of barks were followed by the particular event?" For Elmo, barking most often was followed by verbal attention and the owners parting, physical attention occurred only rarely. The bottom panel of Figure 1 depicts event-based conditional probabilities. These data indicate the proportion of events that followed barking. These data answer the question, "of all the times that a particular event occurred (e.g., verbal attention), what 
proportion of the event followed barking?" Thus, a higher proportion indicates greater dependency. For Elmo, both verbal attention and parting were much more likely to occur following barking than to occur at other times; $81 \%$ of verbal attention followed barking and $93 \%$ of parts followed barking. In contrast, physical attention was more likely to occur at times other than following barking, only 33\% of physical attention followed barking. Thus, most of the verbal attention and owner parting that occurred followed barking.

Behavior pathways derived from the FAI (top panel) and SDA (bottom panel) are depicted in Figure 2. For Elmo, environment-behavior relations suggested by the FAI were supported by the results of the SDA; in the presence of owners hugging, owner attention (especially verbal attention) and owners parting were the events most likely maintaining barking.

Iggy

The results of the descriptive assessment for Iggy are depicted in Figures 3-5. Figure 3 depicts the proportion of intervals during which jump and toy-carrying occurred when visitors arrived. Overall, Iggy engaged in jumping during an average of $29 \%$ of intervals. Although a slight decreasing trend is evident in jumping, during the last three sessions visitors entered the home and immediately sat in a chair whereas visitors in previous sessions entered and kneeled on the floor to interact with Iggy. With the exception of the first and last sessions, toy-carrying never occurred. Due to the slight change in stimulus conditions (owners sitting in a chair versus kneeling), only the first three sessions were used for calculating conditional probabilities as owners reported this behavior was more typical "visitor" behavior.

Antecedent proportions are depicted in Figure 4 and proportions for consequence events are depicted in Figure 5. The top panel of Figure 4 depicts behavior-based conditional probabilities for antecedent events. This figure shows that off all the events measured, physical attention was 
the event most likely to precede a jump - $44 \%$ of jumps were preceded by physical attention. In the bottom panel of Figure 4 the proportion of events that preceded problem behavior (eventbased conditional probabilities) are depicted. Interestingly, physical attention (and all events with the exception of providing a toy) evoked jumping only infrequently; only $20 \%$ of all physical attention was followed by jumping. In contrast, providing a toy was followed by jumping in $67 \%$ of intervals scored. However, it should be noted that tangible delivery only occurred on three occasions (all during the same session) throughout all the observation sessions. These occasions were part of a game the visitor was playing with Iggy. Thus, on these occasions, Iggy grabbed the delivered toy and subsequently made physical contact (i.e., met the criteria for a jump) with the visitor. Due to this unique circumstance, further analysis of tangible delivery as a relevant antecedent for problem jumping was disregarded.

Figure 5 depicts behavior-based (top panel) and event-based (bottom panel) conditional probabilities for consequence events for Iggy. The top panel shows that jumps were often followed by verbal and physical attention and rarely by prompts, hind scratch or tangible delivery. The bottom panel indicates that only $38 \%$ and $34 \%$ of all verbal and physical attention (respectively) were delivered following a jump. Thus, much of the verbal and physical attention was being delivered at times other than following a jump. Likewise, the majority of prompts, hind scratches and tangible deliveries did not follow a jump.

Behavior pathways derived from the FAI (top panel) and SDA (bottom panel) are depicted in Figure 6. For Iggy, environment-behavior relations suggested by the FAI were somewhat supported by the results of the SDA. The top panel of Figure 6 (FAI) shows that owners described visitor attention as the event preceding jumping. The results from the SDA suggested that physical attention from visitors often did precede jumping, but that most physical attention 
(approximately 80\%) was not followed by jumps. Owners also described visitor attention as the event maintaining jumping. However, almost two-thirds of verbal and physical attention delivered did not follow jumping. In other words, much of the attention being delivered was delivered not contingent on jumping. It is possible that there was something different or unique about the attention that preceded or followed jumping. For instance, different visitors certainly used different words and tone when delivering verbal attention and also used different types of physical contact. It is possible that specific tones or types of touch were more likely to follow or precede jumping than others. Only an empirical analysis of various tones and physical contact types would reveal these events as relevant.

\section{Stanley}

Hug condition. Results obtained in the descriptive assessment with Stanley during hugging are depicted in Figure 7. The top panel of Figure 7 indicates the proportion of 30 -s hugs in which barking occurred over five sessions. Stanley barked during the majority of hugging sessions; the mean intervals scored with barking was $64 \%$ across sessions.

The behavior-based probabilities (middle panel) reveal that barking was followed by targeted owner responses only intermittently, but that verbal attention occurred most often-50\% of barks were followed by verbal attention. In contrast, physical attention and parting were less likely to occur following barking. Event-based probabilities (bottom panel) reveal that, of the three events scored, only parting was more likely to occur following barking than to occur independent of Stanley's barking; $62 \%$ of parts occurred following barking. In contrast, only $48 \%$ of verbal attention and $17 \%$ of physical attention followed barking.

Behavior pathways derived from the FAI (top panel) and SDA (bottom panel) are depicted in Figure 8. Environment-behavior relations suggested by the FAI were supported by the results 
of the SDA; in the presence of owners hugging, owner attention (especially verbal attention) and owners parting were the events most likely maintaining barking.

Arrivals condition. Results of the descriptive assessment, conducted when owners arrived, are depicted in Figures 9-11. Figure 9 depicts the proportion of intervals during which jump and toy-carrying occurred. The mean proportion of intervals with jumps over four sessions was $15 \%$ and somewhat variable (with a range of 8-26\%). For toy-carrying, the range over four sessions was also variable (with a range of $0-23 \%$ ) with an average of $11 \%$. Antecedent proportions are depicted in Figure 10 and proportions for consequence events are depicted in Figure 11. Figure 10 (top panel) depicts behavior-based conditional probabilities for antecedent events. This figure shows that of all the events measured, verbal attention was the event most likely to precede jumping ( $50 \%$ of jumps were preceded by verbal attention) followed by attention to another dog (39\% of jumps were preceded by the owner attending to another dog). Physical attention and prompts preceded jumps only occasionally. No jump was ever preceded by tangible delivery.

Figure 10 (bottom panel) shows that the proportion of events that preceded problem behavior (event-based conditional probabilities) was $20 \%$ or less across all the events. It is possible again, that the specific type of attention was the relevant variable and was not detected with this assessment. In addition, the relatively low proportion of attention to other dog that preceded jumping may have been because often the owners would attend to the other dog when Stanley was in another part of the house; he often returned while this was going on or ending and, although jumping occurred, most often it was more than $5 \mathrm{~s}$ after the end of attention to the other dog and so was not scored.

Figure 11 depicts behavior-based (top panel) and event-based (bottom panel) conditional probabilities for consequence events for Stanley in the Arrivals condition. The top panel shows 
that a large proportion of jumps were followed by verbal and physical attention respectively (61\% and $71 \%$ of jumps were followed by verbal and physical attention respectively); few jumps were followed by attention to another dog or prompts. No jump was ever followed by delivery of a tangible. The bottom panel of Figure 11 indicates that only a small proportion of all events measured were delivered following a jump. In other words, most of these events were delivered at times other than following jumping.

Behavior pathways derived from the FAI (top panel) and SDA (bottom panel) are depicted in Figure 12. The hypothesized environment-behavior relation suggested by the FAI for antecedent events was not supported by the data from the SDA. Owners reported that the event most likely to precede jumping was the owners carrying an object (see Figure 12 top panel). However, in the SDA, it was observed that owners often did not carry an object upon arrival and jumping was still highly likely to occur. Rather, the SDA suggested that the relevant events were the owner attending to Stanley or attending to another dog.

The hypothesized environment-behavior relation suggested by the FAI for consequence events was supported by the results of the SDA; when either or both owners arrived home, owner attention was the event most likely maintaining jumping. It is important, however, to note that $65-75 \%$ of owner attention was not delivered contingent on jumping (see Figure 11 bottom panel). Once again, the differential quality of the attention may have been an important but unreported variable as mentioned above.

From these data, specific antecedent conditions and the hypothesized maintaining variables were tested in Assessment 2.

Assessment 2: Contingency Manipulation 
The purpose of Assessment 2 was to manipulate variables hypothesized to be maintaining problem behavior identified in Assessment 1. Thus, this assessment consisted of contingency manipulations to test the hypotheses and to identify the specific environment-behavior relations contributing to the problem behavior(s). At the completion of the study, a multi-component intervention was developed for each owner and dog as necessary.

Method

\section{Participants and Setting}

The participants were the same as those from Assessment 1. The setting was that in which the problem behavior occurred most often as identified in the descriptive assessment. For Iggy, the setting was in the living room of his owner's home which included the door through which visitors entered. The visitors included the same three females and one male from Assessment 1. For Elmo, the setting was the living room of his owners' home and his owners participated as "huggers." For Stanley Arrivals, the setting was the front yard entry and the foyer of his owners' home which included the entry door through which the owners typically entered when arriving home. Both the male and female owner individually participated in the arrivals. Stanley's Hug assessment was a multi-element assessment, thus the settings included three rooms in the owners' home; the kitchen, the living room, and the dining room. Once again, both of Stanley's owners participated as "huggers."

\section{Behavioral Definitions and Interobserver Agreement}

Target behaviors and environmental events were defined and coded as in Assessment 1. All sessions were videotaped for coding by trained observers using Noldus Observer coding software. Observer training and interobserver agreement were as described above for the descriptive assessment. All events and responses except barks for Elmo and Stanley (Hug) were 
measured as partial-interval. Barking for Elmo and Stanley (Hug) was scored as a frequency measure.

Interobserver agreement was calculated on $40 \%$ of sessions; percentages for each condition are included in Table 7. The mean total interobserver agreement for data recorded as partial interval across all participants was 99\% (range 92-100\%) for jump, 95.5\% (range 88-100\%) for toy, $96 \%$ (range $78-100 \%$ ) for verbal attention, $97 \%$ (range $84-100 \%$ ) for physical attention, 99\% (range 94-100\%) for contact, 99\% (range 91-100\%) for part, 99\% (range 95-100\%) for prompt, and 94\% (range 83-98\%) for attends to other. The total agreement coefficient for barking measured as continuous frequency [Elmo and Stanley (Hug)] was 94.5\% (range 82$100 \%)$.

Owner training.

Owners or visitors implemented the requirements of each condition. Prior to beginning the assessment owners were provided a written description of each condition and, if necessary, received prompts during sessions from the experimenter. The experimenter was available during all sessions to provide verbal guidance regarding the procedural requirements of the conditions. For timed conditions (described below), owners used a stopwatch to ensure conditions were implemented for the required duration.

\section{Design and Procedure}

For each dog, the events included in the contingency manipulation were those identified in the descriptive assessment. For Stanley Arrivals, the descriptive assessment suggested that, in the presence of one or both owners arriving home, attention (physical and/or verbal) and attention to the other dogs were the events most likely to precede problem behavior. The event most likely to follow problem behavior was attention (either physical and/or verbal). 
Contingency manipulations therefore were conducted when owners arrived home. Owners were asked to attend to Stanley periodically and to attend to other dogs, thereby ensuring that likely antecedent events were in place. Attention was provided following jumping or an alternative behavior depending on the condition in effect. For Iggy, the descriptive assessment suggested that, in the presence of visitors arriving at the home, attention (either verbal and/or physical) from visitors was likely to precede jumping, while attention (either verbal and/or physical) was also likely to follow jumping. Contingency manipulations, therefore, were conducted when visitors arrived and to ensure antecedent events occurred, visitors were instructed to provide verbal and/or physical attention to Iggy upon arrival. Attention was provided following jumping or an alternate behavior depending on the condition in effect. For both Elmo and Stanley in the presence of owners hugging, observations during the descriptive assessment suggested that attention and termination of hugging were events that frequently followed barking. Therefore, contingency manipulations occurred when owners were hugging (the antecedent event) and attention or termination of hugging was provided following barking or an alternative behavior depending on the condition in effect.

Sessions for all dogs were continued until performance appeared stable based on visual inspection by two independent observers.

\section{Elmo}

Data on frequency of barking were collected during five different conditions manipulated in a reversal design during which both owner attention and parting were manipulated. Data were collected on barks that occurred within the first $40 \mathrm{~s}$ of accumulated hugging for each condition. For example, if individual hugs in each session lasted approximately 5 to $10 \mathrm{~s}$, the session continued and the number of barks occurring during hugs were added together until $40 \mathrm{~s}$ of 
hugging had accumulated; this time parameter was selected based on the average duration of hugging during descriptive assessment sessions. Data also were collected on the number of barks that occurred during the first $40 \mathrm{~s}$ of accumulated non-hug time when owners were delivering various consequences such as part and/or attention.

The "Attention only" condition was designed to evaluate the frequency of barking when verbal attention (but no part) was provided contingent on barking. In this condition, owners hugged for at least 40 consecutive seconds. Hugging continued until Elmo had not barked for 5 consecutive s (to ensure that barking was not inadvertently reinforced by parting; data were coded during only the first $40 \mathrm{~s}$ ). Every time Elmo barked the owners provided brief verbal attention, as typically occurred during the descriptive assessment (e.g., "Elmo, what are you doing?”, “Elmo, you're a crazy dog.”). During “Part only”, each time Elmo barked owners parted for a minimum of $10 \mathrm{~s}$ or until at least $5 \mathrm{~s}$ with no barking had occurred. No attention was provided during the part. After this part, owners began hugging again. This pattern was repeated until a total of $40 \mathrm{~s}$ of hugging had accumulated. The "Part plus attention" condition was designed to evaluate the frequency of barking when both attention (verbal and physical) and part occurred contingent on bark. In this condition, every time Elmo barked owners parted and provided attention for a minimum of $10 \mathrm{~s}$ or until at least $5 \mathrm{~s}$ without barking had occurred and then returned to hugging; this sequence was repeated until a total of $40 \mathrm{~s}$ of hugging had accumulated. No toys were present in the room during any of these conditions.

During the condition "Part plus attention", owners noted that Elmo continued to bark during the part while attention was being delivered and also looked at the top of a cabinet where toys were often stored. Therefore, the condition "Toy" was created to measure the frequency of barking that occurred when the "Part plus attention condition" was implemented in the presence 
of a toy which was placed on the floor in the room prior to the session. Hence, this condition was designed to examine whether or not barking during the part would decrease when Elmo had free access to a toy during the condition. This condition was conducted identically to the "Part plus attention condition" except a toy was present throughout the condition.

The "DRO" condition was designed as an intervention condition. In the "DRO" condition, a differential reinforcement of other behavior (DRO) 5-s schedule was implemented during which part plus verbal and physical attention were provided contingent on at least $5 \mathrm{~s}$ of no barking. The toy was present at all times during this condition. In this condition, owners provided at least $10 \mathrm{~s}$ of attention contingent on at least $5 \mathrm{~s}$ in which no barking occurred. Owners continued this sequence until a total of $40 \mathrm{~s}$ of hugging had accumulated. The "DRO" condition was followed by a reversal to the "Toy" condition to evaluate functional control, and finally a return to the "DRO” condition.

Iggy

Data on the occurrences of jumping and toy carrying per interval were collected during two different conditions during which attention (verbal and/or physical) as a consequence for both the target problem behavior (jumps) and the selected alternative behavior (toy-carrying) was manipulated. Data were collected during the first 2 min of each visit and all visits were separated by 1-5 min. Since more than ten days had passed since the collection of the baseline data in the descriptive assessment (Assessment 1), two baseline probe sessions were conducted prior to beginning the contingency manipulation. Probes were identical to descriptive assessment sessions except, as an oversight the toy basket was not available. Thus, during probes the visitor attended to Iggy when he jumped. 
Since owners identified toy-carrying as an appropriate alternative behavior during which jumping rarely occurred, a toy retrieval and carrying assessment was conducted prior to the subsequent "DRA plus extinction" condition to determine Iggy's rate of compliance to the cue "get your toy." Owners reported that Iggy was already familiar with the prompt "get your toy" and would respond reliably to the prompt. Owners were instructed to practice a few times per day over a 2-day period prior to the retrieval assessment Owners arranged practice time in a quiet room with a toy object placed on the floor or in a toy basket. Owners delivered the verbal prompt "get your toy" and provide 3-5 s of verbal and physical attention when Iggy made oral contact with the toy object. If Iggy did not make contact with toy to verbal prompt alone, a gestural prompt (point) was added to the verbal prompt. Owners allowed one min between prompts. Iggy was considered to have met criteria when he would respond by making oral contact with toy in 4 out of 5 prompts issued. This rate of compliance was verified by the experimenter prior to commencement of the subsequent conditions.

The "DRA plus extinction" condition was designed as an intervention condition to reduce the number of intervals in which jumping occurred and to increase the number of intervals in which toy carrying occurred. In this condition, visitors arrived as usual, knelt, talked to and attempted to pet Iggy for a total of 2 min. A differential reinforcement of alternative behavior (DRA) plus extinction contingency was implemented such that if Iggy jumped, the visitor remained completely still or covered his or her face and turned away as necessary to prevent injury. When jumping had not occurred for at least $5 \mathrm{~s}$, the visitor issued the verbal prompt, "get your toy." If Iggy contacted the toy with his mouth the visitor delivered 3-5 s of verbal and physical attention. If Iggy kept the toy in his mouth, praise was delivered approximately once 
every $5 \mathrm{~s}$. If Iggy dropped the toy, and no jumping had occurred for $5 \mathrm{sec}$, the visitor re-cued Iggy to "get your toy."

In the "Reversal" condition, jumps were followed by verbal and physical attention, but toycarrying was not (i.e., toy-carrying was put on an extinction schedule). This condition was conducted to demonstrate the functional control of jumping and toy carrying by attention manipulation. The "Reversal" condition was followed by a return to the "DRA plus extinction" condition.

Stanley

Arrivals. As with Iggy, data on the occurrences of jumping per interval were collected from two different conditions during which attention (verbal and/or physical) as a consequence for both the target problem behavior (jumps) and the selected alternative behavior (toy-carrying) was manipulated. One to two sessions were conducted per day with each session lasting 4-5 min. Since toy-carrying was also identified an appropriate alternative behavior for Stanley, a toy retrieval assessment identical to that conducted with Iggy (above) was also implemented. Stanley was considered to have met criteria when he would respond by making oral contact with the toy in 4 out of 5 prompts issued. This rate of compliance was verified by the experimenter prior to commencement of the subsequent conditions. In addition, since more than ten days had passed since the collection of the baseline data in the descriptive assessment (Assessment 1), a baseline probe session was conducted prior to beginning the contingency manipulation. The contingencies in effect during the baseline probe session were identical to those observed during the descriptive assessment, that is owners were instructed to respond to Stanley's jumping with attention (verbal and/or physical). 
During the "DRA plus extinction" condition, toy objects were made freely available at all times and the antecedent stimuli identified as occasioning problem behavior (owner attention and attention to other dog) were presented. Owners were instructed to implement consequences as in the "DRA plus extinction" condition implemented with Iggy above. For instance, an owner arrived home as usual, walked into the house and sat, pretended to look at mail, attended to the other dog, or talked briefly to Stanley. All jumps were completely ignored (owner remained completely still). After $5 \mathrm{~s}$ with no jumping, the verbal prompt "get your toy" was issued if Stanley was not already making oral contact with a toy. If Stanley kept the toy in his mouth, praise was delivered approximately once every $5 \mathrm{~s}$. If Stanley dropped the toy, and no jumping had occurred for $5 \mathrm{~s}$, the owner re-cued Stanley to "get your toy." If Stanley jumped with toy object in his mouth (a rare occurrence), he was ignored until at least $5 \mathrm{~s}$ of no jumping had occurred.

In the "Reversal" condition, jumps were followed by attention, but toy-carrying was not (i.e., toy-carrying was put on an extinction schedule). This condition was conducted to demonstrate the functional control of jumping and toy carrying by attention manipulation. The "Reversal" condition was followed by a return to the "DRA plus extinction" condition.

Hug. Data were collected on the frequency of barks that occurred within the first $30 \mathrm{~s}$ of accumulated hugging during each of three separate conditions. The three conditions were alternated in a multi-element design in which both owner attention and part were manipulated. To demonstrate functional control, this assessment was followed by a reversal design in which the condition with the highest frequency of barking was alternated with an extinction condition. To assist in the discriminability of the conditions in the multi-element assessment, three different rooms of the owners' home were used for the three separate conditions. The "Attention only" 
condition was conducted in the living room, the "Part only" condition was conducted in the kitchen and the "Part plus attention" condition was conducted in the dining room. Conditions were varied randomly with the constraint that no more than two conditions of the same type were conducted sequentially and conditions were separated by at least a 10 min inter-condition interval. A maximum of nine sessions were conducted in one day. Each of the three conditions was conducted identically to the same conditions used with Elmo (above) with the exception that the total duration of accumulated hugging was $30 \mathrm{~s}$.

In the reversal design, the condition from the multi-element assessment in which the highest frequency of barking was observed was alternated with an extinction condition designed as an intervention to decrease barking. In this case, the frequency of barking was highest in the "Attention only" condition, so an "Attention only" condition was alternated with an "Extinction" condition to demonstrate the functional control of barking by the manipulation of attention. In the "Attention only" condition, barking was followed by verbal attention from owners. In the "Extinction" condition, barking was ignored. The "Extinction" condition was followed by a return to the "Attention only" condition and finally a return to the "Extinction" condition.

\section{Procedural Integrity}

To assure that the intervention and reversal conditions were implemented with integrity, conditional probabilities were calculated as in the descriptive assessment. Formulas for calculating procedural integrity are depicted in the bottom half of Table 5 (Consequences). If the procedure was implemented with high integrity, then the conditional probabilities would be expected to be close to 0 when an event such as attention was not supposed to follow a target behavior such as jump, or close to 1 when an event such as attention was supposed to follow a target behavior such as toy-carrying. For example, if the intervention required that the owner 
withhold attention following barking, then the probability of attention following barking and the probability of barking preceding attention should be close to or equal to 0 (i.e. no instance of barking would be followed by barking). Likewise, if attention was to be delivered contingent on an alternative behavior such as toy-carrying, then the probability of attention following toycarrying and the probability of toy-carrying preceding attention should be close to or equal to 1 (i.e. all instances of toy-carrying would be followed by attention). Procedural integrity condition probabilities are reported in Table 8.

\section{Results and Discussion}

\section{Elmo}

Figure 13 depicts the frequency of barking during the experimental manipulation conducted with Elmo. In baseline (collected during the descriptive assessment), barking occurred most often during hugging (labeled as contact on the figure); barking rarely occurred after the owners parted (labeled as apart on the figure). When owners provided attention contingent on barking but did not part (in the "Attention only" condition), rates of barking increased by about $75 \%$ to an average of 37.25 barks per $40 \mathrm{~s}$ of accumulated hugging. In the next assessment condition, during which, contingent on barks, the owners parted but provided no attention, rates of barking during contact decreased slightly (although not to levels observed in baseline); interestingly, barking increased markedly during apart. In fact, the frequency of barking was higher during the times the owners were apart then when they were hugging. The data from these two manipulations suggested that perhaps parting and attention served as the reinforcer and therefore, in the next phase a brief termination of hugging and attention followed barking. Interestingly, elevated rates of barking both during hugging and during time apart was observed. Based on owner report that, during the assessment, Elmo frequently barked while looking at a toy on a 
shelf, the next phase was identical to the previous except that the toy was available to Elmo. This resulted in a marked decrease in barking in both conditions, although barking continued to occur when Elmo's owners were hugging. As a result, a new condition was implemented (labeled DRO), during which owners provided at least $10 \mathrm{~s}$ of attention contingent on at least $5 \mathrm{~s}$ in which no barking occurred. In this condition, responding dropped to zero during owner hugs and during apart. After a brief reversal to evaluate functional control, this condition was re-instituted and response suppression was again achieved.

Iggy

Figure 14 depicts the proportion of intervals in which jumping and toy-carrying occurred as a function of experimental conditions conducted with Iggy. During the baseline sessions (collected during the descriptive assessment), when jumping and toy-carrying were followed by attention, jumping was occurring during approximately $30-40 \%$ of the initial session intervals and during $40-50 \%$ of intervals in the baseline probe sessions. Toy-carrying rarely occurred except for during the first baseline session. During the "DRA plus extinction" condition when jumping was placed on an extinction schedule and toy-carrying was followed by visitor attention, the proportion of intervals with jumps fell to less than $20 \%$ of intervals and the proportion of intervals with toy-carrying rose to between $60-100 \%$. A return to baseline conditions (in which jumping and toy carrying were followed by attention) did not show a definitive decrease in toycarrying, therefore, toy-carrying was placed on extinction at session 14. After session 14, toycarrying fell during the next three sessions but then returned to initial (higher) levels. The proportion of intervals with jumping overall did increase slightly but never returned to levels observed during the baseline sessions. In three sessions, no jumping at all occurred. In the final "DRA plus extinction" condition, toy-carrying returned to higher levels and the proportion of 
intervals with jumping fell to or near zero. These data suggest that the "DRA plus extinction" condition was an effective intervention to reduce jumping

Stanley

Arrivals. Figure 15 depicts the proportion of intervals with jumping and toy-carrying during owner arrivals as a function of two experimental conditions conducted with Stanley. The proportion of intervals with jumping during baseline (collected during the descriptive assessment) ranged from approximately $10-25 \%$ while toy-carrying ranged from approximately $0-20 \%$. In this condition, jumping was often followed by attention while toy-carrying was not. A baseline probe session showed jumping occurred during $20 \%$ of intervals and toy-carrying did not occur at all. In the first assessment condition ("DRA plus extinction"), jumping was placed on an extinction schedule and toy-carrying was followed by owner attention. Under these contingencies, the number of intervals during which jumping occurred eventually fell to zero while toy-carrying rose to between approximately $30-70 \%$ of intervals. During a reversal to the baseline condition to demonstrate functional control (in which owners attended to jumping but ignored toy-carrying) there was a slight increase in jumping and a decrease in toy-carrying. In the final "DRA plus extinction" condition, the proportion of intervals in which jumping occurred again fell to or near zero (an $87 \%$ reduction from baseline levels) and toy-carrying increased approximately $85 \%$ from the baseline condition. Again, as with Iggy above, the DRA with extinction was an effective intervention for decreasing jumping.

\section{Stanley}

Hug. Figure 16 top depicts the frequency of barks as a function of three separate experimental conditions conducted with Stanley. The frequency of barking was highest in the conditions in which barks were followed by attention (both the "Attention only" and "Part plus 
attention" conditions) and rarely occurred in the condition in which barks were followed only by the owners parting ("Part only"). The results of these manipulations suggested that attention served as the reinforcer. Therefore, the bottom of Figure 16 compares the frequency of barking when barks were followed by attention (labeled "Attn only" on the graph) and when barks were not followed by attention (labeled "Extinction" on the graph). When owners did not provide attention contingent on barking, rates of barking decreased by approximately $60 \%$ to an average of 13 barks per $30 \mathrm{~s}$ of accumulated hugging in the "Extinction" condition. A brief reversal demonstrated a return to higher rates and a return to the "Extinction" condition resulted in a reduction in barking with rates eventually falling to zero. Sessions 8, 9, 20 and 21 depict sessions during which rates barking were high in the "Extinction" condition and may be attributed to extinction bursts

\section{Procedural Integrity}

Procedural integrity was evaluated by calculating the proportion of environmental events that followed target behavior. Both event-based and behavior based proportions were calculated using the "Consequences" formulas from Table 5. The resulting conditional probabilities are depicted in Table 8. Overall, the owners or visitors implemented the conditions with a high degree of integrity.

Elmo

For Elmo, data from the descriptive assessment (Assessment 1) suggested that when owners hugged, $89 \%$ of barks were followed by verbal attention and over $74 \%$ of barks were followed by the owners parting. Thus, in Assessment 2, owners were asked to manipulate the delivery of attention and part in five different conditions. Owners implemented these contingencies with a high degree of integrity. In the "Attention only" condition, both event- and behavior-based 
conditional probabilities for the event attention were very high indicating that of all barks occurring, most were followed by owner attention and of all attention delivered all followed barks. For the event part (which was not an event manipulated in this condition) the owners never parted following barks. In the "Part only" condition, owners implemented the condition perfectly. Owners never delivered attention following barks, all barks were followed by part, and when part occurred it was always following a bark. In the "Part plus attention" condition in which all barks were supposed to be followed by part and attention, all barks were followed by part and attention while most (73\%) of the attention and all of the parts delivered followed bark. In the "Toy" condition (identical to "Part plus attention" but including a toy), the proportions were very similar to the proportions from the "Part plus attention" condition. In the "DRO" condition in which owners were instructed to withhold attention and part following barking, owners implemented this condition perfectly as well as indicated by the zero proportions for both events (i.e., the owners never provided attention or part contingent on barking).

Iggy

For Iggy, data from the descriptive assessment (Assessment 1) suggested that when visitors arrived and attended to Iggy, $66 \%$ of jumps were often followed by verbal attention and $73 \%$ of jumps were followed by physical attention. Thus, in Assessment 2, visitors were asked to manipulate the delivery of attention and part in two different conditions. During the "DRA plus extinction" condition when owners were instructed to ignore jumping and provide attention contingent on toy-carrying, the behavior-based conditional probabilities indicate that owners provided attention following $36 \%$ of jumps and $82 \%$ of toy-carrying. A perfect implementation of the "DRA plus extinction" condition would have meant that $0 \%$ of jumps and $100 \%$ of toycarrying would have been followed by attention. The discrepancy between the observed value of 
$36 \%$ and the preferred value of $100 \%$ for the behavior-based probability for jumping reflects the fact that owners often did not wait $5 \mathrm{~s}$ after a jump occurred to provide attention if the jump was immediately followed by toy-carrying. Of the 14 jumps that were followed by owner attention, 10 of these jumps were immediately followed by Iggy making contact with a toy. Hence, both the jump and the toy-carrying were followed by owner attention. This explains the relatively high behavior-based conditional probability for jumping. The low event-based proportions for jumping indicate the visitors' correct procedural implementation. Of all the attention being delivered to Iggy, most (96\%) was not contingent on jumping; the high event-based proportion for toy-carrying indicates that of all the attention being delivered, 91\% was delivered contingent on toy-carrying. The "Reversal 1" and "Reversal 2" conditions represent the first three and last ten sessions respectively in the reversal condition. In "Reversal 1" (first three sessions), visitors were instructed to provide attention contingent on toy-carrying and jumping However, in "Reversal 2", visitors were instructed to continue to attend to jumping but to ignore toy-carrying. The conditional probabilities reflect this change in condition requirements. Behavior-based conditional probabilities for jump were high in both reversal conditions while behavior-based proportions decreased for toy-carrying from $80 \%$ in "Reversal 1 " to $10 \%$ in "Reversal 2 ". Likewise, event-based proportions for toy-carrying also decreased from "Reversal 1" to "Reversal 2" reflecting the change in the delivery of attention However, event-based probabilities were relatively low for jump in both reversal conditions indicating that much of the attention being provided was being provided non-contingent on jumping and may reflect the visitors' attempts at providing attention to occasion jumping.

Stanley 
Arrivals. Data from the descriptive assessment conducted with Stanley when owners arrived home suggest that jumps were often followed by verbal and physical attention from owners (e.g., approximately $60 \%$ of jumps were followed by verbal attention and $70 \%$ of jumps were followed by physical attention). In Assessment 2, when owners were asked to implement contingencies consistent with the various experimental conditions designed to assess owner attention as a reinforcing event, owners were reasonably accurate. During the "DRA plus extinction" condition when owners were instructed to ignore jumping and provide attention contingent on toy-carrying, the behavior-based conditional probabilities indicate that owners provided attention following $36 \%$ of jumps and $65 \%$ of toy-carrying. A perfect implementation of the "DRA plus extinction" condition would have meant that $0 \%$ of jumps and $100 \%$ of toy-carrying would have been followed by attention. The discrepancy between the observed values the preferred values reflects two issues. The first is that owners often did not wait $5 \mathrm{~s}$ after a jump occurred to provide attention if the jump was immediately followed by toy-carrying. Of the 9 jumps that were followed by owner attention, 5 of these jumps were immediately followed by Stanley making contact with a toy. Hence, both the jump and the toy-carrying were followed by owner attention. This explains the relatively high behavior-based conditional probability for jumping. The second issue addresses the relatively low behavior-based conditional probability for toycarrying. This may be explained by noting that Stanley often carried his toy throughout many intervals and owners were not exact in their delivery of attention every $5 \mathrm{~s}$. Hence, many instances of toy-carrying were not followed by owner attention. The event-based probabilities, however, reflect a higher measure of procedural integrity. The low event-based proportion for jumping indicates that of all the attention being delivered to Stanley, most (98\%) was not contingent on jumping; the high event-based proportion for toy-carrying indicates that of all the 
attention being delivered, $80 \%$ was delivered contingent on toy-carrying With the above discrepancies noted, it appears that owners were reasonably accurate at implementing the procedures of this experimental condition.

During the "Reversal" condition in which owners were instructed to provide attention contingent on jumping and to ignore toy-carrying, the relative proportions were reversed from the "DRA plus extinction" condition for behavior-based probabilities (i.e., proportions were higher for jumping and lower for toy-carrying) . The high behavior-based proportion for jumping ( $82 \%$, meaning $82 \%$ of jumps were followed by attention) was similar to proportions from the descriptive assessment (e.g., approximately $60 \%$ of jumps were followed by verbal attention and $70 \%$ of jumps were followed by physical attention). Event-based probabilities, however, were relatively low for both jump and toy. A low proportion of attention following toy-carrying would be expected in this condition, but the low proportion of attention following jumps would not. This indicates that much of the attention being delivered was being delivered non-contingent on jumping or toy-carrying. The relatively low proportion of attention delivered following jumping (15\%) may reflect owners' attempts at providing attention to occasion jumping.

Hug. For Stanley Hug, data from the descriptive assessment (Assessment 1) suggested that when owners hugged, half of barks were followed by verbal attention and over half $(62 \%)$ of parts occurred following barking. Thus, in Assessment 2, owners were asked to manipulate the delivery of attention and part in four different conditions. Owners implemented these contingencies with a high degree of integrity. In the "Attention only" condition, both event- and behavior-based conditional probabilities for the event attention were very high indicating that of all barks occurring, most were followed by owner attention and of all attention delivered most followed barks. For the event part (which was not an event manipulated in this condition) the 
low behavior-based proportion (5\%) indicates that of all the times barks occurred, few were ever followed by part. The high event-based proportion for this event (100\%--suggesting that of all the times part occurred, every occurrence followed a bark) is anomalous and would not be expected in this condition. However, this high number can be explained by the fact that throughout all the "Attention only" sessions, part only occurred one time during the examined initial $30 \mathrm{~s}$ of hugging and when it did occur it happened to follow a bark, thus, the calculated probability equaled $100 \%$. In the "Part only" condition, owners implemented the condition perfectly. Owners never delivered attention following barks, all barks were followed by part, and when part occurred it was always following a bark. In the "Part plus attention" condition in which all barks were supposed to be followed by part and attention, all barks were followed by part and attention while most (73\%) of the attention and all of the parts delivered followed bark. Owners also implemented the "Extinction" condition perfectly by providing no attention or part following barking. Overall, the data indicate that owners implemented all the conditions with a high degree of integrity.

\section{General Discussion}

Currently no published strategies exist demonstrating the systematic assessment of problem behavior exhibited by dogs as a function of environmental antecedents and consequences. In addition, outcome reports from extant treatment strategies usually take the form of written descriptions of multi-component packages (Lindsay, 2001). The purpose of this study was to demonstrate the use of systematic descriptive and experimental analyses to identify controlling environment-behavior relations that could potentially be used in the development of functionbased interventions to reduce or eliminate problem behavior in dogs. The first assessment involved systematically assessing problem behavior and environmental events to develop 
hypotheses regarding the variables maintaining problem behavior using a descriptive assessment method. A computer-based data recording technique was used which allowed for the coding of all occurrences of problem behavior and select environmental events and the calculation of both event-based and problem-based conditional probabilities. The second assessment was an experimental manipulation to test the hypotheses derived from the first assessment. The results of Assessment 1 were used to develop experimental conditions to identify a functional relation between the problem behavior and the identified maintaining variable in Assessment 2. The integrity of procedural implementation was also assessed via conditional probabilities. Results suggested that attention from humans was a reinforcing event that could be manipulated to increase and decrease problem behavior in pet dogs. Owners and visitors implemented various procedures with a relatively high degree of integrity.

The following discussion addresses the emerging development of standardized conditions and events in the functional assessment of dog behavior, the potential advantages and disadvantage of computerized data collection, the utility of direct versus indirect assessment, assignment of mechanism, and suggestions for future studies including further elucidation of the role of human attention in the development and maintenance of problem behavior, and the general role of functional assessment in the successful treatment of problem behaviors in pet dogs.

\section{Identification of events affecting responding}

The events and target behaviors measured in this study were identified via owner interview and observations of video tape collected from owners' homes in an attempt to systematically identify environmental variables maintaining problem behavior. While target behaviors were relatively easy to identify (i.e., the behaviors that the owners found problematic), the events that 
may have been maintaining the behaviors depended on identifying as many environmental events occurring in temporal relation to the target behavior as could be identified by the owner and observed on the video tapes. Evaluating such a broad range of events was necessary since the assessment of dog problem behavior using functional assessment has not been developed to the extent it has in human populations and standardized conditions and standard events have not been established. While several events were recorded (e.g., tangible delivery, prompt, part, hind scratch, etc.), human attention in the form of verbalizations addressed to the dog and/or physical contact with the dog was the event most likely to occur following problem behavior, and when manipulated as an independent variable, was shown to have a functional relation to problem behavior in all three dogs participating in this study. This will come as no surprise to those who have spent time with dogs including owners, trainers, veterinarians, etc., but the systematic identification of owner attention as a reinforcer for the target behaviors measured in this study suggests that in future functional assessment studies, human attention should be considered as a potential maintaining variable and a condition in which attention is manipulated should become a standard condition in any functional analysis of problem behavior in dogs.

\section{Data collection}

A potential pragmatic drawback to this study is that the data collected relied on computerized data collection software that may not be readily available to practitioners. In addition, the significant amount of time necessary to train observers to use such software may also be prohibitory. Computerized data collection is useful in the early stages of technology development because it allows for precise analyses of the temporal relation between environmental events and target responses. As functional assessment methods for dogs are developed and refined, alternative data collection procedures should be explored. Other methods 
for behavioral data collection other than by use of computerized software (such as the use of paper and pencil data recording methods) have a long history (e.g., Bijou, Peterson \& Ault, 1968) and may provide a useful and accessible alternative for data analyses similar to those used in this study. Therefore, it would be valuable to examine the level of agreement between computer-based data recording and paper and pencil-based data recording techniques in the analysis of dog behavior.

\section{Indirect assessment utility}

Indirect assessment techniques are widely recommended and used in the assessment of problem behavior in dogs; however, their utility in the accurate identification of environmentbehavior relations has not been demonstrated with dogs. In general, the results of this study provide preliminary evidence that owners are able to identify relevant antecedents and consequences for problem behavior with good accuracy. One possible exception was that Stanley's owners identified the antecedent event as "the owner carrying an object the dog wants." Because owners rarely carried objects with them during the assessment, this hypothesis could not be substantiated. The second exception was during Elmo's assessment in which the owners did not identify the toy as a relevant component necessary to establish attention as a reinforcer. In this case, the dog stopped barking during the delivery of the purported reinforcer (attention) only when the toy was present. Both of these exceptions support the use of direct assessments in conjunction with indirect assessments in the successful evaluation of problem behavior, although it may be possible to train owners to become better observers, and hence, to produce more valid reports.

It should also be noted that a potential limitation in generalizing from the relatively high accuracy of owner reports in this study to all owner reports is that the owners in this study either 
had a background in Behavior Analysis or shared their homes with someone else who did. It is possible that this particular history may have influenced their ability to identify relevant events. Owners lacking this specific history may have been less accurate in their identification.

\section{Mechanism attribution}

The use of a descriptive evaluation to assess problem canine behavior as used here is not entirely new (e.g. Tortora, 1980, 1983; Young, 1988), but the use of the results from such an evaluation to demonstrate functional relations and to assist in the development of a functionbased treatment is new in the dog problem behavior literature. One of the advantages of a functional assessment, as used here, is the development of an effective intervention derived from the measurement of observable behavior and not on putative unobservable (hypothetical) constructs. For instance, Stanley (Hug condition) and Elmo both barked when their respective owners hugged. This could be construed by some as a "jealousy" or possibly even a response to "protect" one or the other of the owners. However, as demonstrated here, it was not necessary to defer to an unobservable construct to develop an accurate description of the behavior (Assessment 1) and a successful function-based intervention (Assessment 2). Placing the mechanism for behavior change in the environment allowed for a direct manipulation of a measurable variable (i.e., the delivery or non-delivery of owner attention) resulting in a demonstrable difference in the occurrence of the problem behavior (barking).

\section{Future studies}

Subsequent studies may consider the specific role of attention in the creation and maintenance of problem behavior in dogs. An interesting observation from the data presented here is the large amount of attention that is delivered to pet dogs by humans. While human attention often followed problem behavior, it occurred more often at other times (see Iggy and 
Stanley Arrivals in Assessment 1). These data suggest that dogs receive a lot of attention from humans that is not contingent on problem behavior. Despite the amount of attention being provided to dogs that was not contingent on problem behavior, a functional relation between human attention and problem behavior in dogs was demonstrated in Assessment 2. A possible explanation for this seemingly unlikely result could be that the type of verbal and/or physical attention being delivered differed across deliveries. Another possible explanation is that level of deprivation occurring prior to attention delivery may have been relevant. So, for example, problem behavior may have been more likely to occur after relatively longer intervals with no human attention [e.g., Stuart's arrival sessions which occurred after the owners had been away for some time; Iggy's sessions during which individuals who had not been in the house (and thus available to attend) arrived]. This parameter was not manipulated in this study but would be worth studying in future evaluations.

Future research also may include additional measures of the specific consequences and behaviors maintained by other contingencies. In this study, the consequential events verbal and physical attention often co-occurred and, therefore, were not manipulated separately in Assessment 2. However, it would be of interest to determine whether verbal or physical attention would be differentially effective as a consequence. It is possible that verbal attention as a reinforcer is better described as a conditional reinforcer while physical attention may be considered a primary reinforcer in a class with food or water. In the current study, physical attention often took the form of scratching or stroking areas of the dog which it could not scratch itself (top of head, chest, back, rump, etc.). From this conceptualization, one might expect that physical attention might maintain problem behavior more effectively than verbal attention (which requires an association with a primary reinforcer such as food, water, or scratching) 
periodically to maintain its efficacy. Future studies might consider a differential analysis of physical and verbal attention.

The specific reinforcement process responsible for maintaining a particular problem behavior should also be considered. The problem behaviors exhibited by the participant dogs in this study were maintained by a positive reinforcement contingency as demonstrated in Assessment 2. Other problem behaviors, however, may be maintained by negative reinforcement. As noted in the introduction to this paper, one of the leading problem behaviors reported in pet dogs is aggressive behavior. Much aggressive behavior in pet dogs may be conceptualized as a behavior that results in escape from or avoidance of an aversive stimulus. For instance, a dog that growls when being groomed may exhibit this behavior because it has resulted in the termination of grooming in the past. This behavior (which could be characterized as an escape response) could easily become an avoidance response if growling occurs when the grooming tool becomes visible and results in the delay or removal of the grooming session or tool. Because aggression is such a serious problem behavior in dogs, a functional assessment to identify the relevant variables and to derive function-based interventions would be of great value. The current study suggests that the techniques of functional assessment can be utilized to describe functional relations between problem dog behavior (here, jumping and barking) and owner behavior (here, attention) and suggests that such techniques could also be used similarly to treat behavior maintained by other contingencies such as aggressive behavior and negative reinforcement. 


\section{References}

Anderson, C.M. \& Long, E.S. (2002). Use of a structured descriptive assessment methodology to identify variables affecting problem behavior. Journal of Applied Behavior Analysis, 35 (2), 137-154.

Anderson, C.M. \& English, C.L. (in press). Use of the structured descriptive assessment with typically developing children. Behavior Modification.

Appleby, D.L., Bradshaw, J.W.S., \& Casey, R.A. (2002). Relationship between aggressive and avoidance behaviour by dogs and their experience in the first six months of life. The Veterinary Record, 150, 434-438.

Beaver, B.V. (1980). Mental lapse aggression syndrome. Journal of the American Animal Hospital Association, 16, 937-939.

Beaver, B. (1983). Clinical classification of canine aggression. Applied Animal Ethology, 10, 35 43.

Beaver, B.V. (1993). Profiles of dogs presented for aggression. Journal of the American Animal Hospital Association, 29, 564-569.

Beaver, B.V. (1994). Differential approach to aggression by dogs and cats. The Veterinary Quarterly, 16 (1), 48S.

Beaver, B.V. (1999). Canine behavior: A guide for veterinarians. Philadelphia: W.B. Saunders Co.

Bijou, S.W., Peterson, R.F., \& Ault, M.H. (1968). A method to integrate descriptive and experimental field studies at the level of data and empirical concepts. Journal of Applied Behavior Analysis, 1, 175-191. 
Blackshaw, J.K. (1991). An overview of types of aggressive behaviour in dogs and methods of treatment. Applied Animal Behaviour Science, 30, 351-361.

Borchelt, P.L. (1983). Aggressive behavior of dogs kept as companion animals: Classification and influence of sex, reproductive status and breed. Applied Animal Ethology, 10, 45-61.

Borchelt, P.L. \& Voith, V.L. (1996). Dominance aggression in dogs. In P.L. Borchelt \& V.L. Voith (Eds.), Readings in Companion Animal Behavior (pp. 230-239. Trenton, New Jersey: Veterinary Learning Systems.

Burch, M.R. \& Bailey, J.S. (1999). How dogs learn. New York: Howell.

Cameron, D.B. (1997). Canine dominance-associated aggression: Concepts, incidence, and treatment in a private behavior practice. Applied Animal Behaviour Science, 52, 265-274.

Carr, E.G. (1977). The motivation of self-injurious behavior: A review of some hypotheses. Psychological Bulletin, 84 (4), 800-816.

Carr, E.G., Yarbrough, S.C., \& Langdon, N.A. (1997). Effects of idiosyncratic stimulus variables on functional analysis outcomes. Journal of Applied Behavior Analysis, 30 (4), 673-686.

Carr, J.E., Hatfield, D.B., Austin, J.L., \& Bailey, J.S. (1998). Interpreting functional analysis results using the real-time recording of independent and dependent variables. Behavioral Interventions, 13, 61- 66.

Dunlap, G., Kern, L., de Perczel, M., Clarke, S., Wilson, D., Childs, K.E., White, R. \& Falk, G.D. (1993). Functional analysis of classroom variables for students with emotional and behavioral disorders. Behavioral Disorders, 18 (4), 275-291. 
English, C.L. (2004). Evaluation of the treatment utility of the analog functional analysis and the structured descriptive assessment. Unpublished doctoral dissertation, West Virginia University, Morgantown, WV.

Grognet, J. \& Parker, T. (1992). Further diagnosis and treatment of canine dominance aggression. Canadian Veterinary Journal, 33, 409-410.

Hanley, G. P., Iwata, B. A., \& McCord, B.E. (2003). Functional analysis of problem behavior: A review. Journal of Applied Behavior Analysis, 36 (2), 147-185.

Hart, B.L. (1985). Behavior of domestic animals. New York: W.H. Freeman \& Company.

Hayes, S.C. \& Follette, W.C. (1992). Can functional analysis provide a substitute for syndromal classification? Behavioral Assessment, 14, 345-365.

Hayes, S.C. \& Follette, W.C. (1993). The challenge faced by behavioral assessment. European Journal of Psychological Assessment, 9 (3), 182-188.

Hayes, S.C., Nelson, R.O., \& Jarrett, R.B. (1987). The treatment utility of assessment: A functional approach to evaluating assessment quality. American Psychologist, 42 (1), 963-974.

Houpt, K.A. (1985). Companion animal behavior: A review of dog and cat behavior in the field, the laboratory and the clinic. Cornell Veterinarian, 75, 248-261.

Houpt, K.A. (1998). Domestic animal behavior for veterinarians and small animal scientists $\left(3^{\text {rd }}\right.$ ed.). Ames, Iowa: Iowa State University Press.

Houpt, K.A. \& Reisner, I.R. (1995). Behavioral disorders. In S.J. Ettinger \& E.C. Feldman (Eds.), Textbook of veterinary internal medicine, 4th ed. (pp. 179-187). Philadelphia: W.B. Saunders. 
Iwata, B.A., Dorsey, M.F., Slifer, K.J., Bauman, K.E., \& Richman, G.S. (1994). Toward a functional analysis of self-injury. Journal of Applied Behavior Analysis, 27, 197-209. (Reprinted from Analysis and Intervention in Developmental Disabilities, 2, 3-20, 1982).

Iwata, B.A., Pace, G.M., Cowdery, G.E., \& Miltenberger, R.G. (1994). What makes extinction work? An analysis of procedural form and function. Journal of Applied Behavior Analysis, $27(1), 131-144$.

Iwata, B.A., Kahng, S., Wallace, M.D., Lindberg, J.S. (2000). The functional analysis model of behavioral assessment. In J. Austin \& Carr, J.E. (Eds.), Handbook of applied behavior analysis (pp. 61-89). Reno, NV: Context Press.

Juarbe-Diaz, S.V. \& Houpt, K.A. (1996). Comparison of two antibarking collars for treatment of nuisance barking. Journal of the American Animal Hospital Association, 32, 231-235.

Knol, B.W. (1987). Behavioural problems in dogs. The Veterinary Quarterly, 9 (3), 226-234.

Lerman, D.C. \& Iwata, B.A. (1993). Descriptive and experimental analysis of variables maintaining self-injurious behavior. Journal of Applied Behavior Analysis, 26, 293-319.

Lindsay, S. R. (2001). Handbook of applied dog behavior and training: Volume two: Etiology and assessment of behavior problems. Ames, Iowa: Iowa State University Press.

Line, S., \& Voith, V.L. (1986). Dominance aggression of dogs towards people: Behavior profile and response to treatment. Applied Animal Behaviour Science, 16, 77-83.

Mace, F. C. \& Lalli, J.S. (1991). Linking descriptive and experimental analyses in the treatment of bizarre speech. Journal of Applied Behavior Analysis, 24, 553-562.

Miller, P. \& Donaldson, J. (2001). The power of positive dog training. New York: Wiley Publishing. 
Moyer, K.E. (1968). Kinds of aggression and their physiological basis. Communications in Behavioral Biology, 2, 65-87.

Mugford, R. A. (1984). Behaviour problems in the dog. In R.S. Anderson (Ed.), Nutrition and behaviour in dogs and cats (pp. 207-215). Oxford: Pergamon Press.

Neef, N.A. (Ed.). (1994). Functional analysis approaches to behavioral assessment and treatment [Special Issue]. Journal of Applied Behavior Analysis, 27(2).

Northrup, J., Wacker, D., Sasso, G., Steege, M., Cigrand, K., Cook, J., \& DeRaad, A. (1991). A brief functional analysis of aggressive and alternative behavior in an outclinic setting. Journal of Applied Behavior Analysis, 24 (3), 509-522.

O’Neill, R.E., Horner, R.H., Albin, R.W., Sprague, J.R., Storey, K., \& Newton, J.S. (1997). Functional assessment and program development for problem behavior: A practical handbook. (2 ${ }^{\text {nd }}$ Ed.). Pacific Grove, CA: Brooks/Cole Publishing Co.

Overall, K.L. (1993). Canine aggression. Canine Practice, 18 (5), 32-34.

Overall, K. (1997). Clinical behavioral medicine for small animals. St. Louis, Missouri: Mosby.

Pelios, L., Morren, J., Tesch, D. \& Axelrod, S. (1999). The impact of functional analysis methodology on treatment choice for self-injurious and aggressive behavior. Journal of Applied Behavior Analysis, 32 (2), 185-195.

Polsky, R.H. (1995). User's guide to the scientific and clinical literature on dog and cat behavior ( $2^{\text {nd }}$ ed.). Los Angeles: Animal Behavior Counseling Services, Inc.

Pryor, K. (1999). Don't shoot the dog: The new art of teaching and training. Revised Edition. New York: Bantam. 
Reisner, I.R. (1997). Assessment, management, and prognosis of canine dominance-related aggression. Veterinary Clinics of North America: Small Animal Practice, 27 (3), 479-495.

Reisner, I. R. (2003). Differential diagnosis and management of human-directed aggression in dogs. Veterinary Clinics of North America: Small Animal Practice, 33, 303-320.

Reisner, I.R., Erb, H.N., \& Houpt, K.A. (1994). Risk factors for behavior-related euthanasia among dominant-aggressive dogs: 110 cases (1989-1992). Journal of the American Veterinary Medical Association, 205 (6), 855-863.

Repp, A.C., Felce, D., \& Barton, L.E. (1988). Basing the treatment of stereotypic and selfinjurious behaviors on hypotheses of their causes. Journal of Applied Behavior Analysis, 21 (3), 281-289.

Sasso, G.M., Reimers, T.M., Cooper, L.J., Wacker, D., Berg, W., Steege, M., Kelly, L., \& Allaire, A. (1992). Use of descriptive and experimental analyses to identify the functional properties of aberrant behavior in school settings. Journal of Applied Behavior Analysis, 25 (4), 809-821.

Scotti, J.R., Morris, T.L., McNeil, C.B., \& Hawkins, R.P. (1996). DSM-IV and disorders of childhood and adolescence: Can structural criteria be functional. Journal of Consulting and Clinical Psychology, 64 (6), 1177-1191.

Sherman, C.K., Reisner, I.R., Taliaferro, L.A., Houpt, K.A. (1996). Characteristics, treatment, and outcome of 99 cases of aggression between dogs. Applied Animal Behaviour Science, 47, 91-108.

Skinner, B. F. (1953). Science and human behavior. New York: The Free Press.

Taylor, J., \& Miller, M. (1997). When timeout works some of the time: The importance of treatment integrity and functional assessment. School Psychology Quarterly, 12 (1), 4-22. 
Tortora, D.F. (1980). Applied animal psychology: The practical implications of comparative analysis. In M.R. Denny (Ed.), Comparative Psychology: An Evolutionary Analysis of Animal Behavior (pp. 267-294). New York: John Wiley \& Sons.

Tortora, D.F. (1983). Safety training: The elimination of avoidance-motivated aggression in dogs. Journal of Experimental Psychology: General, 112 (2), 176-214.

Voith, V.L. \& Borchelt, P.L. (1982). Diagnosis and treatment of dominance aggression in dogs. Veterinary Clinics of North America: Small Animal Practice, 12 (4), 655-663.

Voith, V.L. \& Borchelt, P.L. (1996). History taking and interviewing. In V.L. Voith \& P.L. Borchelt (Eds.), Readings in companion animal behavior (pp. 42-47). Trenton, New Jersey: Veterinary Learning Systems.

Wells, D.L. (2001). The effectiveness of a citronella spray collar in reducing certain forms of barking in dogs. Applied Animal Behaviour Science, 73, 299-309.

Williams, N.G. \& Borchelt, P.L. (2003). Full body restraint and rapid stimulus exposure as a treatment for dogs with defensive aggressive behavior: Three case studies. International Journal of Comparative Psychology, 16, 226-236.

Wise, J.K. \& Yang, J.J. (1994). Dog and cat ownership, 1991-1998. Journal of the American Veterinary Medicine Association, 204 (8), 1166-1167.

Wright, J.C. \& Nesselrote, M.S. (1987). Classification of behavior problems in dogs: Distributions of age, breed, sex and reproductive status. Applied Animal Behaviour Science, 19, 169-178.

Young, M.S. (1982). Treatment of fear-induced aggression in dogs. Veterinary Clinics of North America: Small Animal Practice, 12 (4), 645-653. 
Assessing the Effectiveness 60

Young, M.S. (1988). Aggressive behavior. In R.B. Ford (Ed.), Clinical signs and diagnosis in small animal practice (pp. 135-150). Churchill Livingstone: New York. 


\section{Appendix A}

\section{Functional Assessment Interview \& Behavioral History Form for Dogs}

\begin{tabular}{|l|l|}
\hline Dog's Name & Date \\
\hline Breed & Client Name \\
\hline Age Male/Female Neutered? & Phone \\
\hline Weight & Address \\
\hline Do you plan to breed this dog? & \\
& Other \\
\hline Has this dog ever been bred? & Email \\
\hline
\end{tabular}

Behavioral changes after neutering?

Referral Information

Veterinarian
Other

\section{Early History}

Age obtained

Source

Name/location of breeder

Parent behavior?

Littermate behavior?

How many littermates? Male? Female?

Why this particular breed?

Why this particular puppy from litter?

How many previous owners has your dog had?

Why was the dog given up by previous owners?

\section{Client History}

Ever had dogs before? Yes $\square$ how many? No $\square$

What kind?

Any behavioral issues?

What happened to them? 
How many people share household?

Person Sex Age Schedule Relationship with dog? Types of Games played?

How many other animals share household?

Name Species Breed Age When obtained? Relationship with dog?

Who spend most of the time with the dog?

What kind of games are played most often?

Does your dog pester for attention?

Who does dog pester most frequently?

Who feeds the dog?

Who walks the dog?

Where does the dog sleep?

How many times a day is dog let outside?

How much time does dog spend alone?

Where does he spend alone time?

Do you own a crate?

Where does dog stay when you are gone?

Describe how you act when you leave or return home?

How does your dog react when people visit?

Does your dog ever mount family members?

When does your dog bark/whine/howl?

Does your dog every urinate in response to people or commands?

Does your dog steal food?

Does he/she like to be groomed?

Does your dog jump on you or guests? 
Is your dog coprophagic (i.e. eat stools)?

Chew inappropriate items?

Does your dog roam?

\section{Compliance to Commands}

Percentage of response to command

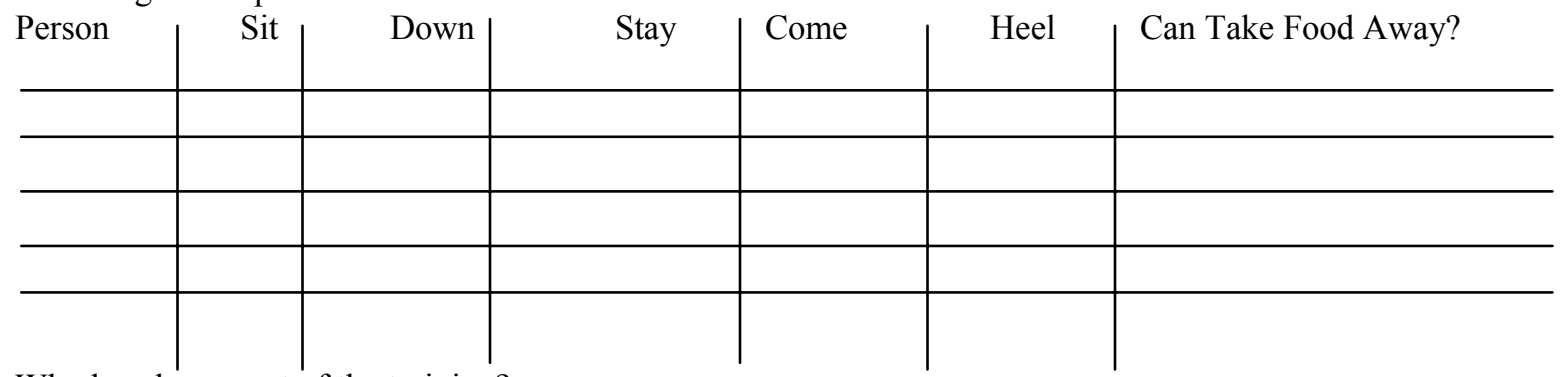

Who has done most of the training?

Method used?

What is most rewarding to your dog?

What is most punishing?

Least rewarding?

Does your dog obey in some places better than others?

Feeding

When is your dog fed?

Where?

What kind of food?

How much?

Do you feed table scraps?

How is dog exercised?

How often?

\section{Medical Information}

Does your dog have any allergies?

What vaccinations has your dog had within last 12 months?

What kind of preventatives is your dog on?

Any medical problems?

\begin{tabular}{l|c|c|c|c} 
Medication & Reason & Dose & Date started & Date ended \\
\hline & & & & \\
\hline & & & & \\
\hline
\end{tabular}

\section{Grooming}

Does your dog like to be groomed? $\square$ Yes $\square$ No

Any areas licked excessively? 
Can you brush your dog's teeth? $\square$ Yes $\quad \square$ No

Trim nails? $\square$ Yes $\square$ No

How was your dog housetrained?

\section{Elimination Behavior}

Does dog ever urinate or eliminate in the house? $\square$ Yes $\square$ No

Are there certain places your dog likes to "mark" more than others?

\section{Behavior Descriptions}

For each of the behaviors, describe what it looks like (topography), how often it occurs per day, week, or month (frequency), how long it lasts (duration), and how damaging or destructive the behaviors are when they occur (intensity).
a.
Behavior
Topography
Frequency
Duration
Intensity
b.
c.
d.
e.
f.
g.
h.
i.
j.

Which of the above behavior are likely to occur together?

Briefly list your dog's daily schedule and check the boxes which correspond to those activities your dog and you seem to enjoy or are associated with problems.

\begin{tabular}{|lll|}
\hline \multicolumn{2}{l}{ Enjoy } & Problem \\
$\square$ & $\square$ & $6: 00$ \\
$\square$ & $\square$ & $7: 00$ \\
$\square$ & $\square$ & $8: 00$ \\
$\square$ & $\square$ & $9: 00$ \\
$\square$ & $\square$ & $10: 00$ \\
$\square$ & $\square$ & $11: 00$ \\
$\square$ & $\square$ & $12: 00$ \\
$\square$ & $\square$ & $1: 00$ \\
& & \\
\end{tabular}

\begin{tabular}{|lll|}
\hline \multicolumn{2}{l}{ Enjoy } & Problem \\
$\square$ & $\square$ & $2: 00$ \\
$\square$ & $\square$ & $3: 00$ \\
$\square$ & $\square$ & $4: 00$ \\
$\square$ & $\square$ & $5: 00$ \\
$\square$ & $\square$ & $6: 00$ \\
$\square$ & $\square$ & $7: 00$ \\
$\square$ & $\square$ & $8: 00$ \\
$\square$ & $\square$ & $9: 00$ \\
& & \\
\end{tabular}


List problem behaviors, when, where, and with whom they are most and least likely to happen: Also list which activity is most and least likely to produce problem behaviors.

\begin{tabular}{|l|l|l|l|l|l|}
\hline \multicolumn{2}{|c|}{ Behaviors: } & 2) & & & \\
\hline $\begin{array}{l}\text { Most likely } \\
\text { when? }\end{array}$ & & & & & \\
\hline $\begin{array}{l}\text { Least likely } \\
\text { when? }\end{array}$ & & & & & \\
\hline $\begin{array}{l}\text { Most likely } \\
\text { with whom? }\end{array}$ & & & & & \\
\hline $\begin{array}{l}\text { Least likely } \\
\text { with whom? }\end{array}$ & & & & & \\
\hline $\begin{array}{l}\text { Most likely } \\
\text { where? }\end{array}$ & & & & & \\
\hline $\begin{array}{l}\text { Least likely } \\
\text { where? }\end{array}$ & & & & & \\
\hline $\begin{array}{l}\text { Activity most } \\
\text { likely to } \\
\text { produce the } \\
\text { behavior: }\end{array}$ & & & & & \\
\hline $\begin{array}{l}\text { Activity least } \\
\text { likely to } \\
\text { produce the } \\
\text { behavior: }\end{array}$ & & & & & \\
\hline
\end{tabular}

Are there particular situations or events not listed above that sometimes seem to "set off" the behaviors, such as particular demands, noises, lights, clothes?

What one thing could you do that would most likely make the undesirable behavior occur?

Briefly describe how your dog's behavior would be affected if:

you stare hard into his/her eyes?

you physically pushed or moved him/her?

you asked him or her to lie down for brushing or nail trimming?

you tried to remove his or her food?

you tried to remove a rawhide or meaty bone?

he or she wanted something but was unable to get it (toy under a chair, on a shelf,etc.)

you left your dog alone in your home for 15 mins?

you left your dog alone in an unfamiliar place for 15 mins?

you tried to touch his ears or teeth? 
Try to identify the specific consequences or outcomes (things he or she gets or things he or she avoids) that occur as a result of your dog's behavior in different situations:

\begin{tabular}{|l|l|l|l|}
\hline Behavior & Particular situation & $\begin{array}{l}\text { What exactly does your dog } \\
\text { get? }\end{array}$ & What exactly does your dog avoid? \\
\hline 1$)$ & & & \\
\hline 2$)$ & & & \\
\hline 3$)$ & & & \\
\hline 4$)$ & & & \\
\hline 5$)$ & & & \\
\hline 6$)$ & & & \\
\hline
\end{tabular}

How does your dog behave around:

\begin{tabular}{|l|l|l|l|l|l|l|}
\hline & plays & avoids & growls & snaps & bites & other \\
\hline Other dogs & & & & & & \\
\hline $\begin{array}{l}\text { Cats or other } \\
\text { small animals }\end{array}$ & & & & & & \\
\hline Familiar adults & & & & & & \\
\hline $\begin{array}{l}\text { Unfamilar } \\
\text { adults }\end{array}$ & & & & & & \\
\hline Children & & & & & & \\
\hline Veterinarian & & & & & & \\
\hline
\end{tabular}




\section{History}

\begin{tabular}{|l|l|l|l|l|}
\hline Behavior & $\begin{array}{l}\text { How long has it } \\
\text { been occurring }\end{array}$ & $\begin{array}{l}\text { Has the severity } \\
\text { changed? }\end{array}$ & $\begin{array}{l}\text { What have you tried to } \\
\text { stop it? }\end{array}$ & $\begin{array}{l}\text { What were the effects } \\
\text { of these attempts? }\end{array}$ \\
\hline 1$)$ & & & & \\
\hline 2$)$ & & & & \\
\hline 3$)$ & & & & \\
\hline 4$)$ & & & & \\
\hline 5$)$ & & & & \\
\hline 6$)$ & & & & \\
\end{tabular}

What is your idea of the perfect dog?

$\square$ I am interested in getting more information but am not too concerned about the problem

$\square$ I would like to change the problem behavior(s), but if I can't I'll keep the dog anyway

$\square$ If I cannot change the behavior I will consider giving the dog away

$\square$ If I cannot change the behavior I will give the dog away

$\square$ If I cannot change the behavior I will euthanize the dog.

Please rate your dog's behavior:

Problems

Very serious

Serious

Not very serious

\begin{tabular}{|l|l|l|l|}
\hline$\# 1$ & & & \\
\hline$\# 2$ & & & \\
\hline$\# 3$ & & & \\
\hline$\# 4$ & & & \\
\hline$\# 5$ & & & \\
\hline
\end{tabular}

Most recent occurrence of very serious problem (s)

Second most recent occurrence of very serious problem(s)

Third most recent occurrence of very serious problem(s)

First occurrence of very serious problem(s) 


\begin{abstract}
Author Note
I would like to express a sincere appreciation to several people who were all influential in seeing this project through to completion. First, I wish to thank Dr. Cindy Anderson for all of her advice, direction and support. This project would not have been possible without her. I also wish to thank Annemarie Woofter and Lynsey Brace for all their time spent coding what seemed like endless sessions. A heartfelt thanks also goes out to the dogs and owners who participated in this study and to my committee members for their time and dedication. Finally, I wish to express my appreciation and gratitude to my husband, Dale, who not only encouraged me during the best and worst times, but stood by me when I needed him most.
\end{abstract}


Table 1.

Aggression Type and Reporting Authors

\begin{tabular}{|c|c|c|c|c|c|c|c|c|c|c|c|c|c|c|}
\hline \multirow[t]{2}{*}{ Type } & \multicolumn{14}{|c|}{ Author(s) Using the Category } \\
\hline & $\mathrm{A}$ & $\mathrm{B}$ & $\mathrm{C}$ & $\mathrm{D}$ & $\mathrm{E}$ & $\mathrm{F}$ & $\mathrm{G}$ & $\mathrm{H}$ & I & $\mathrm{J}$ & $\mathrm{K}$ & $\mathrm{L}$ & M & $\mathrm{N}$ \\
\hline Maternal & $X$ & $X$ & $X$ & & & & $X$ & $X$ & & $X$ & & $X$ & & $\mathrm{X}$ \\
\hline Play & $X$ & & $\mathrm{X}$ & & & & & & & & & & & $\mathrm{X}$ \\
\hline Fear & $X$ & $\mathrm{X}$ & $\mathrm{X}$ & $\mathrm{X}$ & $X$ & $X$ & $\mathrm{X}$ & $X$ & $\mathrm{X}$ & $\mathrm{X}$ & $X$ & $\mathrm{X}$ & $\mathrm{X}$ & $\mathrm{X}$ \\
\hline Pain & $X$ & $X$ & $\mathrm{X}$ & $X$ & & $X$ & & $X$ & $X$ & & & $X$ & & \\
\hline Territorial & $\mathrm{X}$ & & & & $\mathrm{X}$ & $X$ & $X$ & $X$ & $X$ & & $X$ & & $X$ & $\mathrm{X}$ \\
\hline Protective & $X$ & $\mathrm{X}$ & $\mathrm{X}$ & $\mathrm{X}$ & & $\mathrm{X}$ & & & & $\mathrm{X}$ & & $\mathrm{X}$ & & $\mathrm{X}$ \\
\hline Inter-dog & $\mathrm{X}$ & $\mathrm{X}$ & $\mathrm{X}$ & $X$ & $\mathrm{X}$ & $X$ & $X$ & $\mathrm{X}$ & & $\mathrm{X}$ & $\mathrm{X}$ & $X$ & & $\mathrm{X}$ \\
\hline Redirected & $X$ & $X$ & $\mathrm{X}$ & & & $X$ & & & & & & $X$ & & $\mathrm{X}$ \\
\hline Food-related & $X$ & & & & & & & & & & & & $X$ & \\
\hline Possessive & $X$ & $X$ & & $X$ & & & & & & $X$ & & $X$ & & $X$ \\
\hline Predatory & $X$ & $X$ & $\mathrm{X}$ & $X$ & $X$ & $X$ & $\mathrm{X}$ & $X$ & $\mathrm{X}$ & $\mathrm{X}$ & $X$ & $\mathrm{X}$ & $X$ & $\mathrm{X}$ \\
\hline Idiopathic & $X$ & & & & $X$ & & & & & $\mathrm{X}$ & & & & $\mathrm{X}$ \\
\hline Dominance & $X$ & $X$ & $\mathrm{X}$ & $X$ & $\mathrm{X}$ & $\mathrm{X}$ & & $X$ & $X$ & $\mathrm{X}$ & $X$ & $\mathrm{X}$ & & $\mathrm{X}$ \\
\hline Punishment-Elicited & & $\mathrm{X}$ & & $\mathrm{X}$ & & & & & & & & $X$ & & \\
\hline Sibling Rivalry & & & & & $\mathrm{X}$ & & & & & & & & & \\
\hline Learned & & & & $\mathrm{X}$ & & $X$ & $X$ & $X$ & & & & & & $\mathrm{X}$ \\
\hline Irritable & & & & & & $\mathrm{X}$ & $\mathrm{X}$ & & & & & $\mathrm{X}$ & & $\mathrm{X}$ \\
\hline Noise-provoked & & & & & & & & & & $\mathrm{X}$ & & & & \\
\hline
\end{tabular}


Table 1 (continued).

Aggression Type and Reporting Authors

Type Author(s) Using the Category

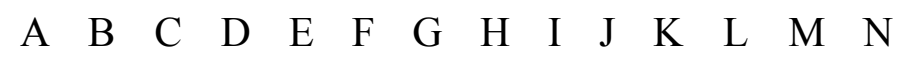

Trained

Stranger-related

Mental lapse

Owner-directed

Child-directed

Avoidance-motivated

Dysfunctional

Low threshold
X

$\mathrm{X}$

$\mathrm{X}$

$\mathrm{X}$

$\mathrm{X}$

$\mathrm{X}$

$\mathrm{X}$

$\mathrm{X}$

$\mathrm{X}$
A. Overall, 1997
B. Borchelt \& Voith, 1996
C. Beaver, 1983
D. Borchelt, 1983
E. Blackshaw, 1991
F. Beaver, 1993 [included 25 types, only the most common non-medically related types are included (i.e., hypothyroid- and epilepsy-related are excluded)]
G. Moyer, 1968
H. Hart, 1985
I. Houpt, 1998 
Table 1 (continued).

J. O'Farrell, 1998

K. Houpt \& Reisner, 1995

L. Young, 1988

M. Reisner, 2003

N. Lindsay, 2001 (excludes pathophysiological) 
Table 2.

Author(s) and Reported Outcomes

\begin{tabular}{|c|c|c|}
\hline Author & $\mathrm{N}$ & Outcome \\
\hline Beaver (1983) [several types of aggression & 71 & $49.3 \%$ successful \\
\hline noted; only competitive (dominance) included & & $33.8 \%$ moderately successful \\
\hline here] & & $16.9 \%$ failure \\
\hline \multirow[t]{4}{*}{ Cameron (1997) Dominance } & 35 & $6 \%$ no change \\
\hline & & $32 \%$ fair \\
\hline & & $44 \%$ good \\
\hline & & $12 \%$ excellent \\
\hline \multirow[t]{3}{*}{ Galac \& Knol (1996) Fear-motivated } & 284 & $75 \%$ improved \\
\hline & & $18 \%$ unchanged \\
\hline & & $7 \%$ deteriorated \\
\hline Knol (1987) (describes multiple behavior & 65 & $25 \%$ good improvement \\
\hline problems, only aggression case outcomes & & $17 \%$ fair improvement \\
\hline \multirow[t]{4}{*}{ included here) } & & $11 \%$ moderate improvement \\
\hline & & $41 \%$ owner disappointed, animal \\
\hline & & replaced, or euthanized \\
\hline & & $6 \%$ incomplete data \\
\hline \multirow[t]{3}{*}{ Line \& Voith (1986) Dominance } & 24 & $21 \%, 90 \%$ improved \\
\hline & & $53 \%, 70 \%$ improved \\
\hline & & $79 \%, 50 \%$ improved \\
\hline
\end{tabular}


Table 2 (continued)

Author(s) and Reported Outcomes

\begin{tabular}{lll}
\hline \multicolumn{1}{c}{ Author } & $\mathrm{N}$ & \multicolumn{1}{c}{ Outcome } \\
\hline Overall (1993); Aggression (general) & (not & $75 \%$ greatly improved \\
& reported) & \\
Overall (1993a); Aggression (general) & (not & $90 \%$ success rate \\
Reisner, Erb \& Houpt (1994) Dominance & reported) & \\
Tortora (1983) (Experiment 2) Avoidance- & 110 & $85 \%$ improved \\
motivated & 36 & Complete reduction \\
Uchida, Dodman, DeNapoli \& Aronson (1997); & 20 & $70 \%$ responded to some degree \\
Dominance & & $20 \%$ “cured" (owner report) \\
\end{tabular}


Table 3 .

Dog Behavior Operational Definitions.

\begin{tabular}{|c|c|c|}
\hline Dog & Label & Definition \\
\hline Stanley (Arrivals) & Jump & the dog's front two paws break contact with the ground and \\
\hline \multirow[t]{2}{*}{ Iggy } & & the dog's body part such as muzzle or paw(s) makes contact \\
\hline & & with a human body part or clothing \\
\hline Stanley (Hug) & Bark & any short punctuated vocalization emitted by the dog that is \\
\hline Elmo & & not a whine or growl \\
\hline Stanley (Hug) & Nudge & Dog's muzzle bumps human body part but is not a sniff or \\
\hline Elmo & & lick \\
\hline Stanley (Arrivals) & Mouth & Dog places teeth on human body part or clothing \\
\hline Iggy & Paw & Dog touches human body part with one paw \\
\hline Stanley (Arrivals) & Toy & Dog makes oral contact with non-food item such as a toy, \\
\hline Iggy & & bone, stick, or ball \\
\hline Stanley (Arrivals) & Compliance & Dog emits prompted response within 5-s following one of \\
\hline Iggy & & the pre-defined owner commands \\
\hline
\end{tabular}


Table 4.

Owner Behavior Operational Definitions and Conditions in Which the Event was Measured

\begin{tabular}{|c|c|c|c|}
\hline Condition & & Label & Definition \\
\hline (Ant.) & (Conseq.) & & \\
\hline Arrivals & Arrivals & $\begin{array}{l}\text { Tangible } \\
\text { delivered }\end{array}$ & $\begin{array}{l}\text { Presents food or toy items to dog and dog } \\
\text { makes contact with item }\end{array}$ \\
\hline Arrivals & $\begin{array}{l}\text { Arrivals } \\
\text { Hug }\end{array}$ & $\begin{array}{l}\text { Physical } \\
\text { Attention }\end{array}$ & $\begin{array}{l}\text { Human initiates physical contact with any } \\
\text { part of dog's body or collar (not restraint; } \\
\text { not to move the dog) }\end{array}$ \\
\hline Arrivals & $\begin{array}{l}\text { Arrivals } \\
\text { Hug }\end{array}$ & $\begin{array}{l}\text { Verbal } \\
\text { Attention }\end{array}$ & $\begin{array}{l}\text { Talking to, scolding, etc. Anything that is } \\
\text { verbal and directed to dog but is not a } \\
\text { prompt }\end{array}$ \\
\hline Arrivals & Arrivals & Prompt & $\begin{array}{l}\text { Pre-defined verbal instructions issued to } \\
\text { the dog. }\end{array}$ \\
\hline Arrivals (Stanley & Arrivals (Stanley & Attends to & When owner directs verbalizations to or \\
\hline only) & only) & Other & touches another dog \\
\hline Hug & & Contact & $\begin{array}{l}\text { When the two owners' hug defined as } \\
\text { physical contact between torsos, and arms } \\
\text { around one another }\end{array}$ \\
\hline & Hug & Part & $\begin{array}{l}\text { Scored when contact is terminated by the } \\
\text { owners separating by at least } 12 \text { inches }\end{array}$ \\
\hline Arrivals (Iggy & Arrivals (Iggy & Hind & Visitor scratches dog on posterior portion \\
\hline only) & only) & Scratch & of back just above tail for at least 2 seconds \\
\hline
\end{tabular}


Table 5 .

Formulas for Calculating Conditional Probabilities

Type

Antecedents

Behavior-based Intervals containing problem behavior that followed a particular event

Intervals scored with problem behavior

Event-based Intervals containing a particular event that preceded problem behavior

Intervals scored with the particular event

\section{Consequences}

Behavior-based Intervals containing problem behavior that preceded a particular event

Intervals scored with problem behavior

Event-based Intervals containing a particular event that followed problem behavior

Intervals scored with the particular event 
Table 6.

Measures of Interobserver Agreement for Descriptive Assessment

\begin{tabular}{|c|c|c|c|c|c|c|c|c|c|}
\hline \multirow[b]{3}{*}{ Behavior } & & \multirow{2}{*}{\multicolumn{2}{|c|}{ Elmo }} & \multirow{2}{*}{\multicolumn{2}{|c|}{ Iggy }} & \multirow{2}{*}{\multicolumn{2}{|c|}{$\begin{array}{l}\text { Stanley } \\
\text { (Arrivals) }\end{array}$}} & \multirow{2}{*}{\multicolumn{2}{|c|}{$\begin{array}{l}\text { Stanley } \\
\text { (Hug) }\end{array}$}} \\
\hline & & & & & & & & & \\
\hline & & $\%$ & Range & $\%$ & Range & $\%$ & Range & $\%$ & Range \\
\hline \multirow[t]{3}{*}{ Jump } & Occurrence & & & 96 & $88-100$ & 95 & $89-100$ & 90 & $80-100$ \\
\hline & Non-occurrence & & & 98 & $94-100$ & 99 & $98-100$ & 98 & $96-100$ \\
\hline & Total & & & 99 & $96-100$ & 99 & $98-100$ & 97 & $97-100$ \\
\hline \multirow[t]{3}{*}{ Nudge } & Occurrence & 100 & 0 & & & & & 100 & 0 \\
\hline & Non-occurrence & 100 & 0 & & & & & 100 & 0 \\
\hline & Total & 100 & 0 & & & & & 100 & 0 \\
\hline \multirow[t]{3}{*}{ Bark } & Occurrence & 98 (Freq). & $98-98$ & & & 88 & $83-92$ & 97 & $94-100$ \\
\hline & Non-occurrence & & & & & 98 & $98-98$ & 97 & $93-100$ \\
\hline & Total & & & & & 98 & $98-98$ & 99 & $97-100$ \\
\hline \multirow[t]{3}{*}{ Paw } & Occurrence & & & 92 & $75-100$ & & & & \\
\hline & Non-occurrence & & & 98 & $95-100$ & & & & \\
\hline & Total & & & 99 & $96-100$ & & & & \\
\hline
\end{tabular}


Table 6. (continued)

Measures of Interobserver Agreement for Descriptive Assessment

\begin{tabular}{|c|c|c|c|c|c|c|c|c|c|}
\hline \multirow[b]{3}{*}{ Behavior } & & \multirow{2}{*}{\multicolumn{2}{|c|}{ Elmo }} & \multirow{2}{*}{\multicolumn{2}{|c|}{ Iggy }} & \multirow{2}{*}{\multicolumn{2}{|c|}{$\begin{array}{c}\text { Stanley } \\
\text { (Arrivals) }\end{array}$}} & \multirow{2}{*}{\multicolumn{2}{|c|}{$\begin{array}{l}\text { Stanley } \\
\text { (Hug) }\end{array}$}} \\
\hline & & & & & & & & & \\
\hline & & $\%$ & Range & $\%$ & Range & $\%$ & Range & $\%$ & Range \\
\hline \multirow[t]{3}{*}{ Mouth } & Occurrence & & & & & & & 100 & 0 \\
\hline & Non-occurrence & & & & & & & 100 & 0 \\
\hline & Total & & & & & & & 100 & 0 \\
\hline \multirow[t]{3}{*}{ Compliance } & Occurrence & & & 100 & 0 & 100 & 0 & & \\
\hline & Non-occurrence & & & 100 & 0 & 100 & 0 & & \\
\hline & Total & & & 100 & 0 & 100 & 0 & & \\
\hline Verbal & Occurrence & 87 & $84-89$ & 84 & $82-87$ & 89 & $88-90$ & 83 & $80-85$ \\
\hline \multirow[t]{2}{*}{ Attention } & Non-occurrence & 96 & $96-96$ & 85 & $83-87$ & 96 & $96-96$ & 93 & $90-95$ \\
\hline & Total & 97 & $97-97$ & 92 & $92-92$ & 97 & $97-97$ & 95 & $94-96$ \\
\hline Physical & Occurrence & 100 & 0 & 91 & $86-100$ & 85 & $81-88$ & 92 & $83-100$ \\
\hline \multirow[t]{2}{*}{ Attention } & Non-occurrence & 100 & 0 & 87 & $80-100$ & 96 & $96-96$ & 95 & $90-100$ \\
\hline & Total & 100 & 0 & 95 & $92-100$ & 97 & $97-97$ & 97 & $94-100$ \\
\hline
\end{tabular}


Table 6. (continued)

Measures of Interobserver Agreement for Descriptive Assessment

\begin{tabular}{|c|c|c|c|c|c|c|c|c|c|}
\hline \multirow[b]{3}{*}{ Behavior } & & \multirow{2}{*}{\multicolumn{2}{|c|}{ Elmo }} & \multirow{2}{*}{\multicolumn{2}{|c|}{ Iggy }} & \multirow{2}{*}{\multicolumn{2}{|c|}{$\begin{array}{c}\text { Stanley } \\
\text { (Arrivals) }\end{array}$}} & \multirow{2}{*}{\multicolumn{2}{|c|}{$\begin{array}{l}\text { Stanley } \\
\text { (Hug) }\end{array}$}} \\
\hline & & & & & & & & & \\
\hline & & $\%$ & Range & $\%$ & Range & $\%$ & Range & $\%$ & Range \\
\hline \multirow[t]{3}{*}{ Contact } & Occurrence & 100 & 0 & & & & & 100 & 0 \\
\hline & Non-occurrence & 100 & 0 & & & & & 100 & 0 \\
\hline & Total & 100 & 0 & & & & & 100 & 0 \\
\hline \multirow[t]{3}{*}{ Part } & Occurrence & 100 & 0 & & & & & 100 & 0 \\
\hline & Non-occurrence & 100 & 0 & & & & & 100 & 0 \\
\hline & Total & 100 & 0 & & & & & 100 & 0 \\
\hline \multirow[t]{3}{*}{ Hind Scratch } & Occurrence & & & 100 & 0 & & & & \\
\hline & Non-occurrence & & & 100 & 0 & & & & \\
\hline & Total & & & 100 & 0 & & & & \\
\hline \multirow[t]{3}{*}{ Prompt } & Occurrence & & & 100 & 0 & 100 & 0 & & \\
\hline & Non-occurrence & & & 100 & 0 & 100 & 0 & & \\
\hline & Total & & & 100 & 0 & 100 & 0 & & \\
\hline
\end{tabular}


Table 6. (continued)

Measures of Interobserver Agreement for Descriptive Assessment

\begin{tabular}{|c|c|c|c|c|c|c|c|c|c|}
\hline \multirow[b]{2}{*}{ Behavior } & & \multicolumn{2}{|l|}{ Elmo } & \multicolumn{2}{|l|}{ Iggy } & \multicolumn{2}{|c|}{$\begin{array}{c}\text { Stanley } \\
\text { (Arrivals) }\end{array}$} & \multicolumn{2}{|c|}{$\begin{array}{l}\text { Stanley } \\
\text { (Hug) }\end{array}$} \\
\hline & & $\%$ & Range & $\%$ & Range & $\%$ & Range & $\%$ & Range \\
\hline Attends to & Occurrence & & & & & 83 & $80-85$ & & \\
\hline \multirow[t]{2}{*}{ Other } & Non-occurrence & & & & & 92 & $87-96$ & & \\
\hline & Total & & & & & 95 & $92-97$ & & \\
\hline Tangible & Occurrence & & & 100 & 0 & & & & \\
\hline \multirow[t]{2}{*}{ Delivery } & Non-occurrence & & & 100 & 0 & & & & \\
\hline & Total & & & 100 & 0 & & & & \\
\hline \multirow[t]{3}{*}{ Toy } & Occurrence & & & 95 & $86-100$ & 87 & $85-88$ & & \\
\hline & Non-occurrence & & & 98 & $94-100$ & 94 & $92-96$ & & \\
\hline & Total & & & 99 & $95-100$ & 95 & $98-100$ & & \\
\hline
\end{tabular}


Table 7.

Measures of Interobserver Agreement for Contingency Manipulation (Assessment 2)

\begin{tabular}{|c|c|c|c|c|c|c|c|c|c|}
\hline \multirow[b]{2}{*}{ Behavior } & & \multicolumn{2}{|l|}{ Elmo } & \multicolumn{2}{|l|}{ Iggy } & \multicolumn{2}{|c|}{$\begin{array}{c}\text { Stanley } \\
\text { (Arrivals) }\end{array}$} & \multicolumn{2}{|l|}{$\begin{array}{c}\text { Stanley } \\
\text { (Hug) }\end{array}$} \\
\hline & & $\%$ & Range & $\%$ & Range & $\%$ & Range & $\%$ & Range \\
\hline \multirow[t]{3}{*}{ Jump } & Occurrence & & & 98 & $85-100$ & 97 & $83-100$ & & \\
\hline & Non-occurrence & & & 99 & $86-100$ & 98 & $90-100$ & & \\
\hline & Total & & & 99 & $92-100$ & 99 & $93-100$ & & \\
\hline \multirow[t]{3}{*}{ Bark } & Occurrence & & & & & & & & \\
\hline & Non-occurrence & & & & & & & & \\
\hline & Total & 94 (Freq.) & $82-100$ & & & & & 95 (Freq.) & $82-100$ \\
\hline \multirow[t]{3}{*}{ Toy } & Occurrence & & & 94 & $78-100$ & 89 & $79-95$ & & \\
\hline & Non-occurrence & & & 89 & $50-100$ & 75 & $40-93$ & & \\
\hline & Total & & & 97 & $92-100$ & 94 & $88-98$ & & \\
\hline Verbal & Occurrence & 95 & $79-100$ & 92 & $73-100$ & 82 & $67-91$ & 99 & $90-100$ \\
\hline \multirow[t]{2}{*}{ Attention } & Non-occurrence & 93 & $80-100$ & 90 & $71-100$ & 86 & $64-97$ & 88 & $50-100$ \\
\hline & Total & 97 & $89-100$ & 96 & $87-100$ & 91 & $78-98$ & 99 & $90-100$ \\
\hline
\end{tabular}


Table 7. (continued)

Measures of Interobserver Agreement for Contingency Manipulation (Assessment 2)

\begin{tabular}{|c|c|c|c|c|c|c|c|c|c|}
\hline \multirow[b]{3}{*}{ Behavior } & & \multirow{2}{*}{\multicolumn{2}{|c|}{ Elmo }} & \multirow{2}{*}{\multicolumn{2}{|c|}{ Iggy }} & \multirow{2}{*}{\multicolumn{2}{|c|}{$\begin{array}{c}\text { Stanley } \\
\text { (Arrivals) }\end{array}$}} & \multirow{2}{*}{\multicolumn{2}{|c|}{$\begin{array}{l}\text { Stanley } \\
\text { (Hug) }\end{array}$}} \\
\hline & & & & & & & & & \\
\hline & & $\%$ & Range & $\%$ & Range & $\%$ & Range & $\%$ & Range \\
\hline Physical & Occurrence & 93 & $75-100$ & 93 & $80-100$ & 90 & $80-100$ & 100 & $96-100$ \\
\hline \multirow[t]{2}{*}{ Attention } & Non-occurrence & 94 & $80-100$ & 91 & $56-100$ & 94 & $83-100$ & 98 & $75-100$ \\
\hline & Total & 95 & $92-100$ & 96 & $84-100$ & 97 & $93-100$ & 100 & $96-100$ \\
\hline \multirow[t]{3}{*}{ Contact } & Occurrence & 97 & $82-100$ & & & & & 100 & $85-100$ \\
\hline & Non-occurrence & 96 & $83-100$ & & & & & 100 & $88-100$ \\
\hline & Total & 98 & $94-100$ & & & & & 100 & $96-100$ \\
\hline \multirow[t]{3}{*}{ Part } & Occurrence & 95 & $60-100$ & & & & & 98 & $78-100$ \\
\hline & Non-occurrence & 99 & $90-100$ & & & & & 99 & $89-100$ \\
\hline & Total & 99 & $91-100$ & & & & & 99 & $92-100$ \\
\hline \multirow[t]{3}{*}{ Prompt } & Occurrence & & & 93 & $0-100$ & 97 & $82-100$ & & \\
\hline & Non-occurrence & & & 99 & $96-100$ & 99 & $94-100$ & & \\
\hline & Total & & & 99 & $96-100$ & 99 & $95-100$ & & \\
\hline
\end{tabular}


Table 7. (continued)

Measures of Interobserver Agreement for Contingency Manipulation

\begin{tabular}{|c|c|c|c|c|c|c|c|c|c|}
\hline \multirow[b]{3}{*}{ Behavior } & & \multirow{2}{*}{\multicolumn{2}{|c|}{ Elmo }} & \multirow{2}{*}{\multicolumn{2}{|c|}{ Iggy }} & \multirow{2}{*}{\multicolumn{2}{|c|}{$\begin{array}{l}\text { Stanley } \\
\text { (Arrivals) }\end{array}$}} & \multirow{2}{*}{\multicolumn{2}{|c|}{$\begin{array}{l}\text { Stanley } \\
\text { (Hug) }\end{array}$}} \\
\hline & & & & & & & & & \\
\hline & & $\%$ & Range & $\%$ & Range & $\%$ & Range & $\%$ & Range \\
\hline Attends to & Occurrence & & & & & 84 & $67-94$ & & \\
\hline \multirow[t]{2}{*}{ Other } & Non-occurrence & & & & & 90 & $73-98$ & & \\
\hline & Total & & & & & 94 & $83-98$ & & \\
\hline
\end{tabular}


Table 8.

Measures of Procedural Integrity

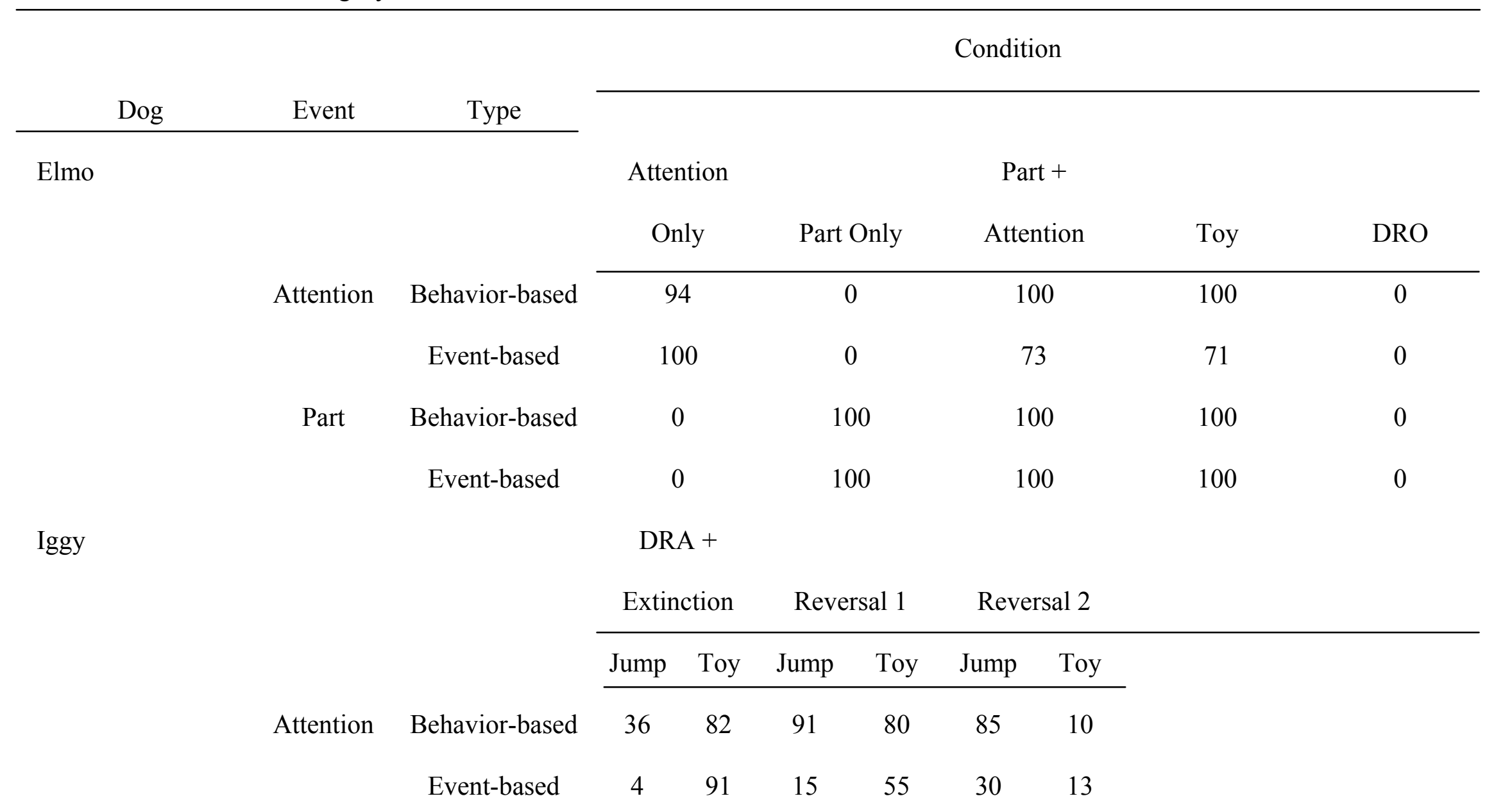


Table 8. (continued)

Measures of Procedural Integrity

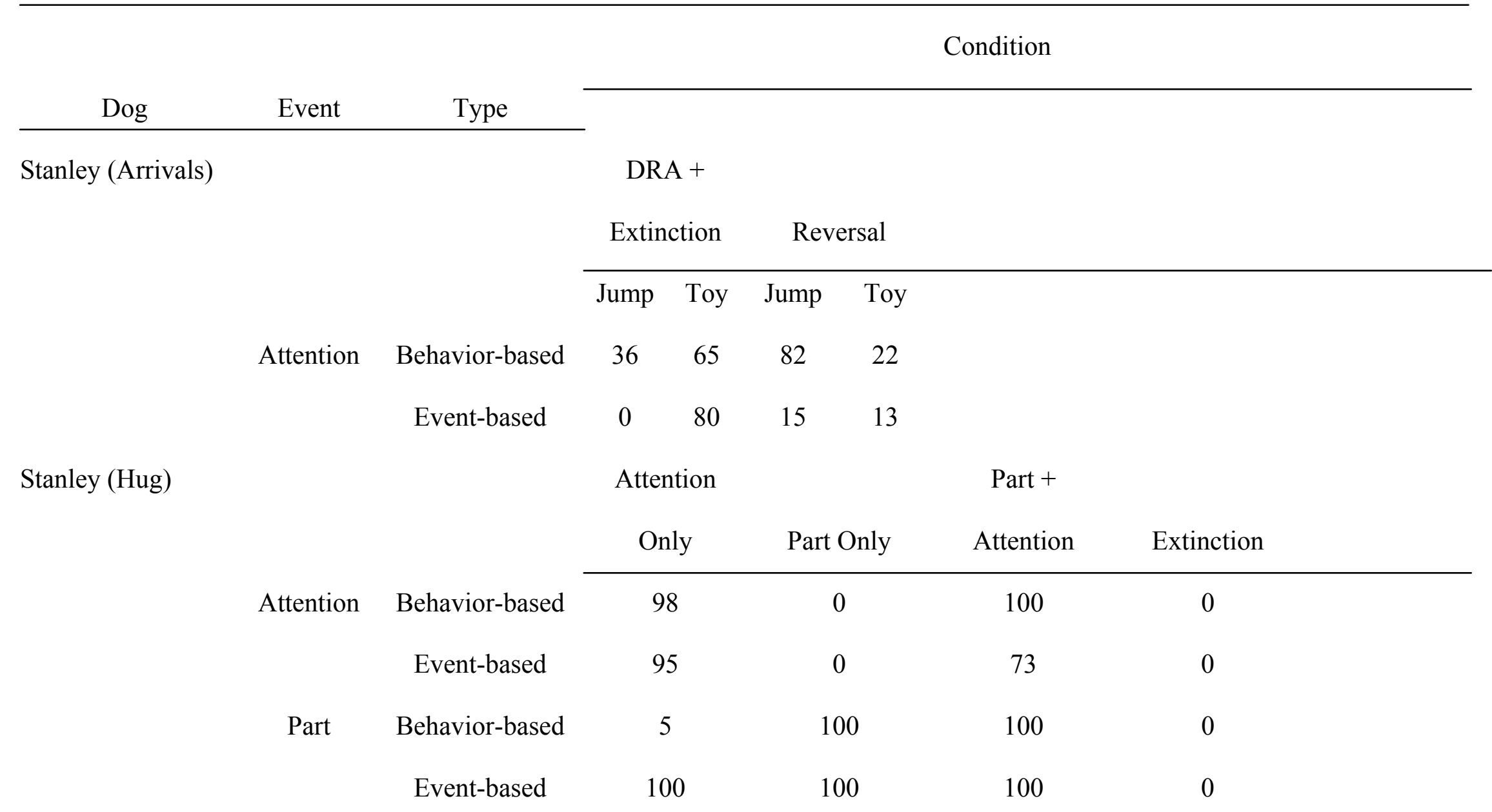




\section{Figure Captions}

Figure 1. (Top) Frequency of barking observed during sessions for Elmo from the descriptive assessment (arrow indicates a session that lasted only $18 \mathrm{~s}$ ); (Middle) behavior-based conditional probabilities; (Bottom) event-based conditional probabilities.

Figure 2. Competing behavior pathways for Elmo as identified by the FAI (top) and the SDA (bottom).

Figure 3. Proportion of intervals with jump or toy-carrying for Iggy during the descriptive assessment.

Figure 4. Antecedent conditional probabilities for Iggy from the descriptive assessment. (Top) behavior-based; (Bottom) event-based.

Figure 5. Consequence conditional probabilities for Iggy from the descriptive assessment; (Top) behavior-based (Bottom) event-based.

Figure 6. Competing behavior pathways for Iggy as identified by the FAI (top) and the SDA (bottom).

Figure 7. (Top) Proportion of contact intervals with barking for Stanley in the hug condition from the descriptive assessment; (Middle). behavior-based conditional probabilities; (Bottom) event-based conditional probabilities.

Figure 8. Competing behavior pathways for Stanley in the hug condition as identified by the FAI (top) and the SDA (bottom).

Figure 9. Proportion of intervals with jump and toy-carrying for Stanley in the arrivals condition during the descriptive assessment.

Figure 10. Antecedent conditional probabilities for Stanley in the arrivals condition during the descriptive assessment; (Top) behavior-based; (Bottom) event-based. 
Figure 11. Consequence conditional probabilities for Stanley in the arrivals condition during the descriptive assessment; (Top) behavior-based; (Bottom) event-based.

Figure 12. Competing behavior pathways for Stanley in the arrivals condition as identified by the FAI (top) and the SDA (bottom).

Figure 13. Frequency of barking in contact and apart during baseline and five experimental conditions for Elmo.

Figure 14. Proportion of intervals with jumping and toy-carrying across sessions and experimental conditions for Iggy.

Figure 15. (Top) Frequency of barks across sessions and three experimental conditions for Stanley in the hug condition; (Bottom) Frequency of barking across two different experimental conditions.

Figure 16. Proportion of intervals with jumping and toy-carrying across sessions and experimental conditions for Stanley in the arrivals condition. 
Assessing the Effectiveness 88
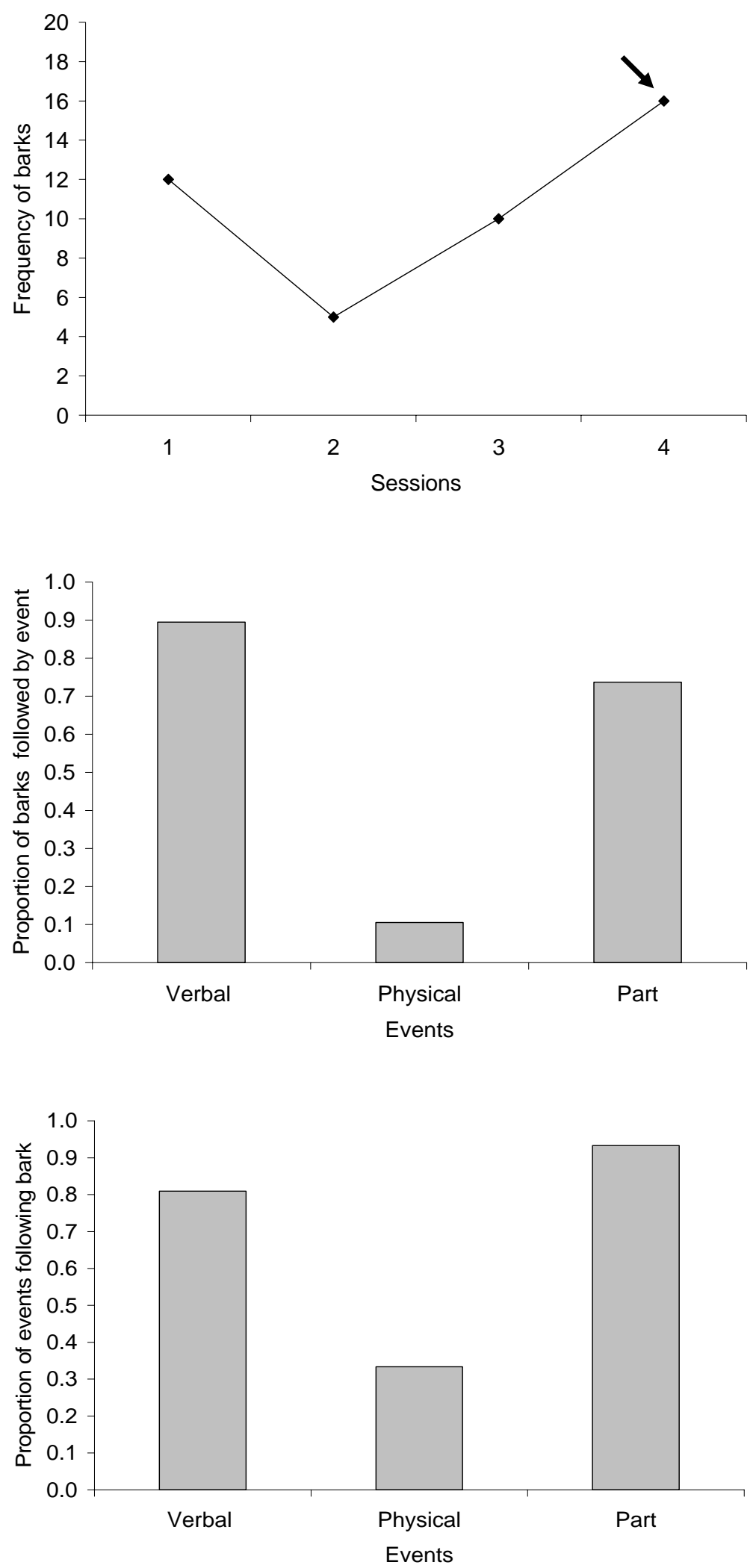

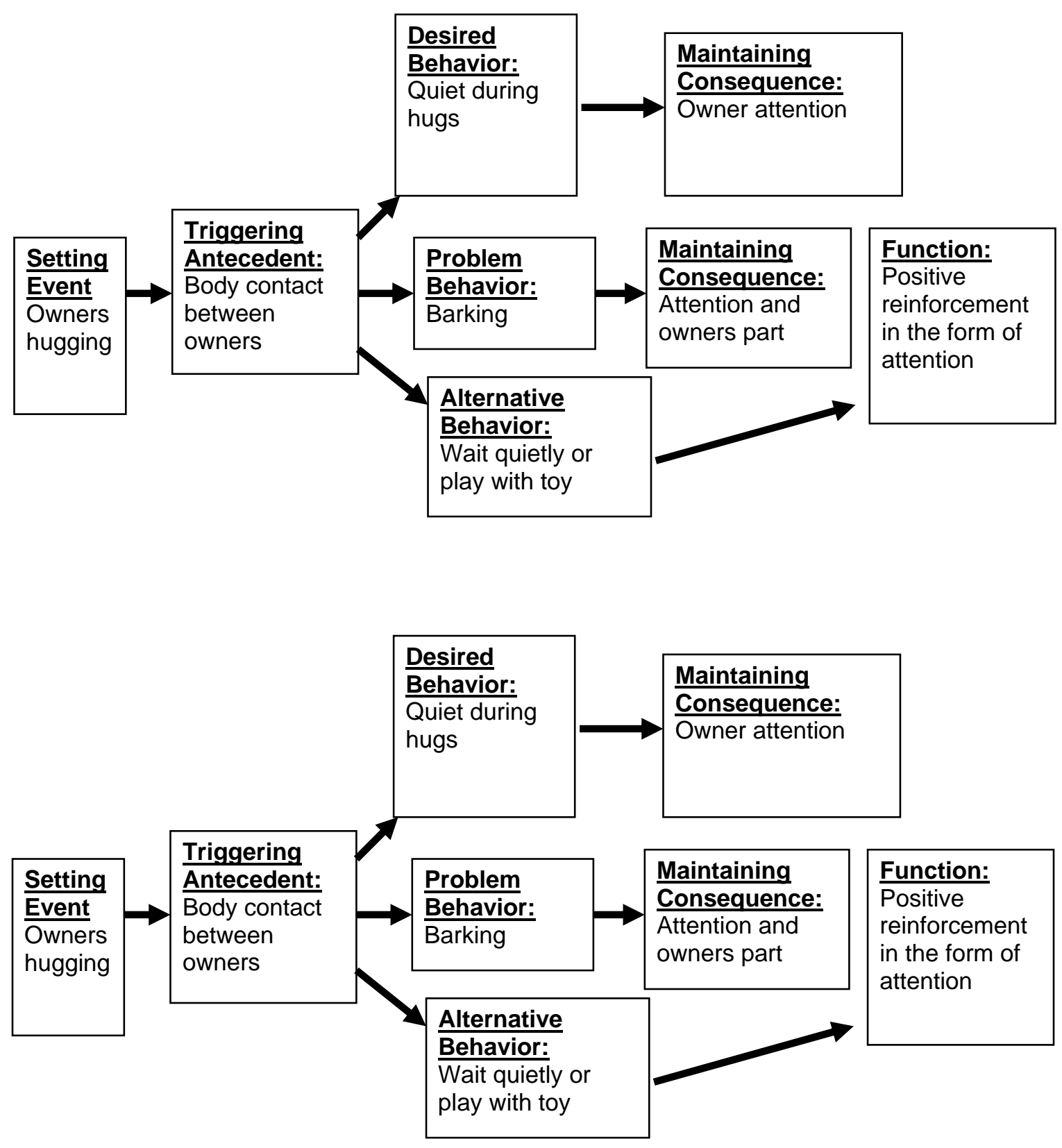
Assessing the Effectiveness 90

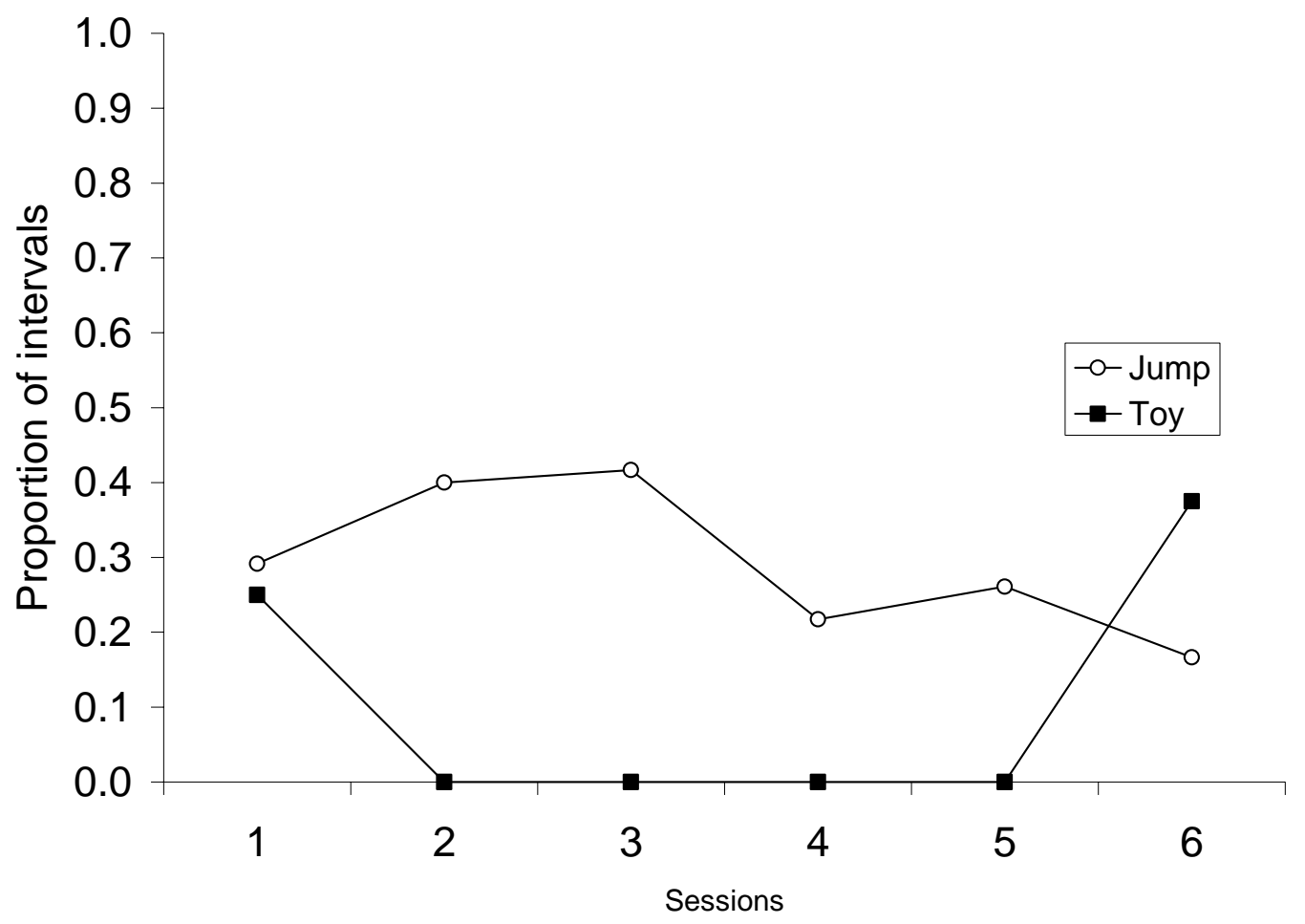



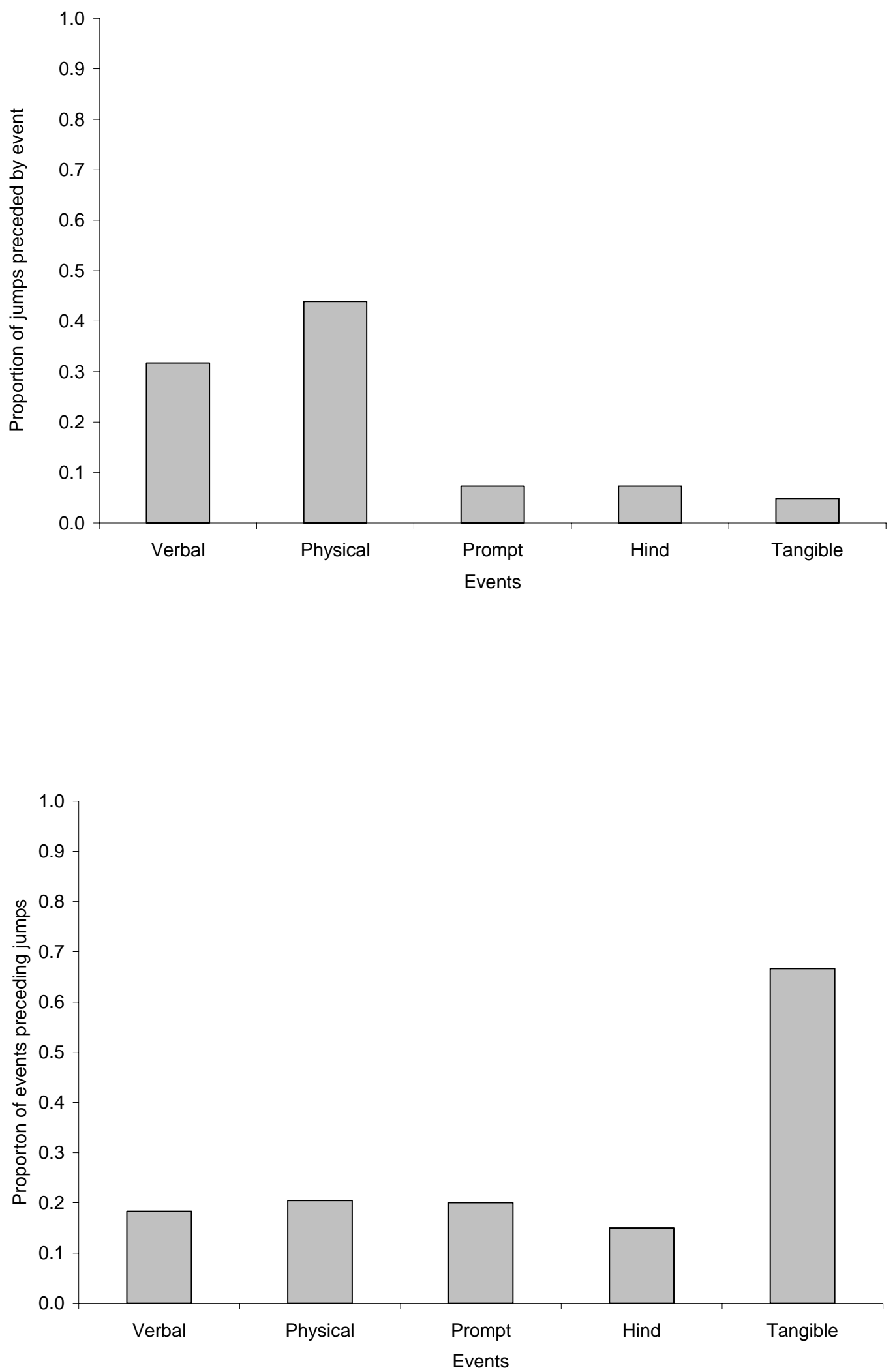
Assessing the Effectiveness 92
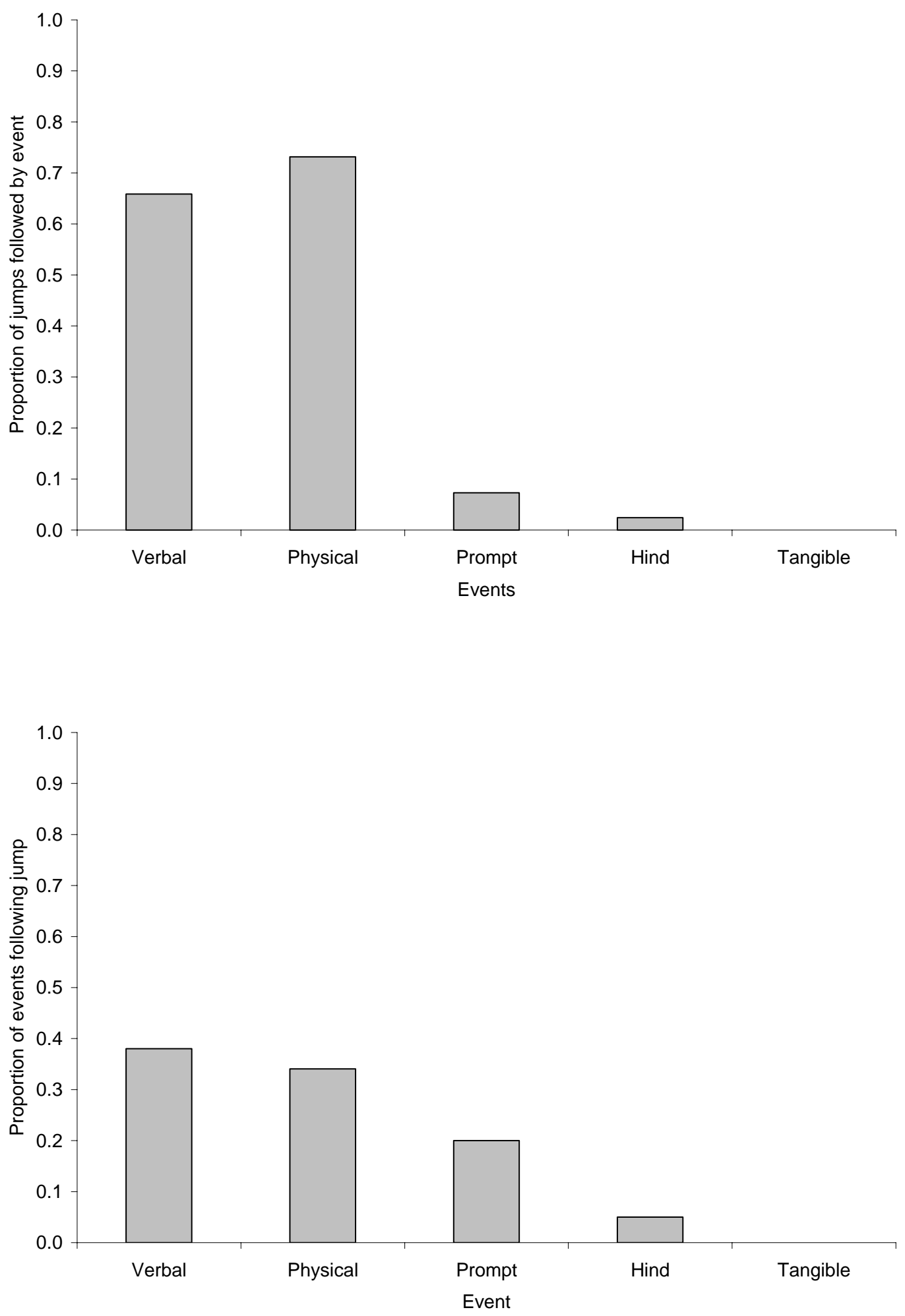

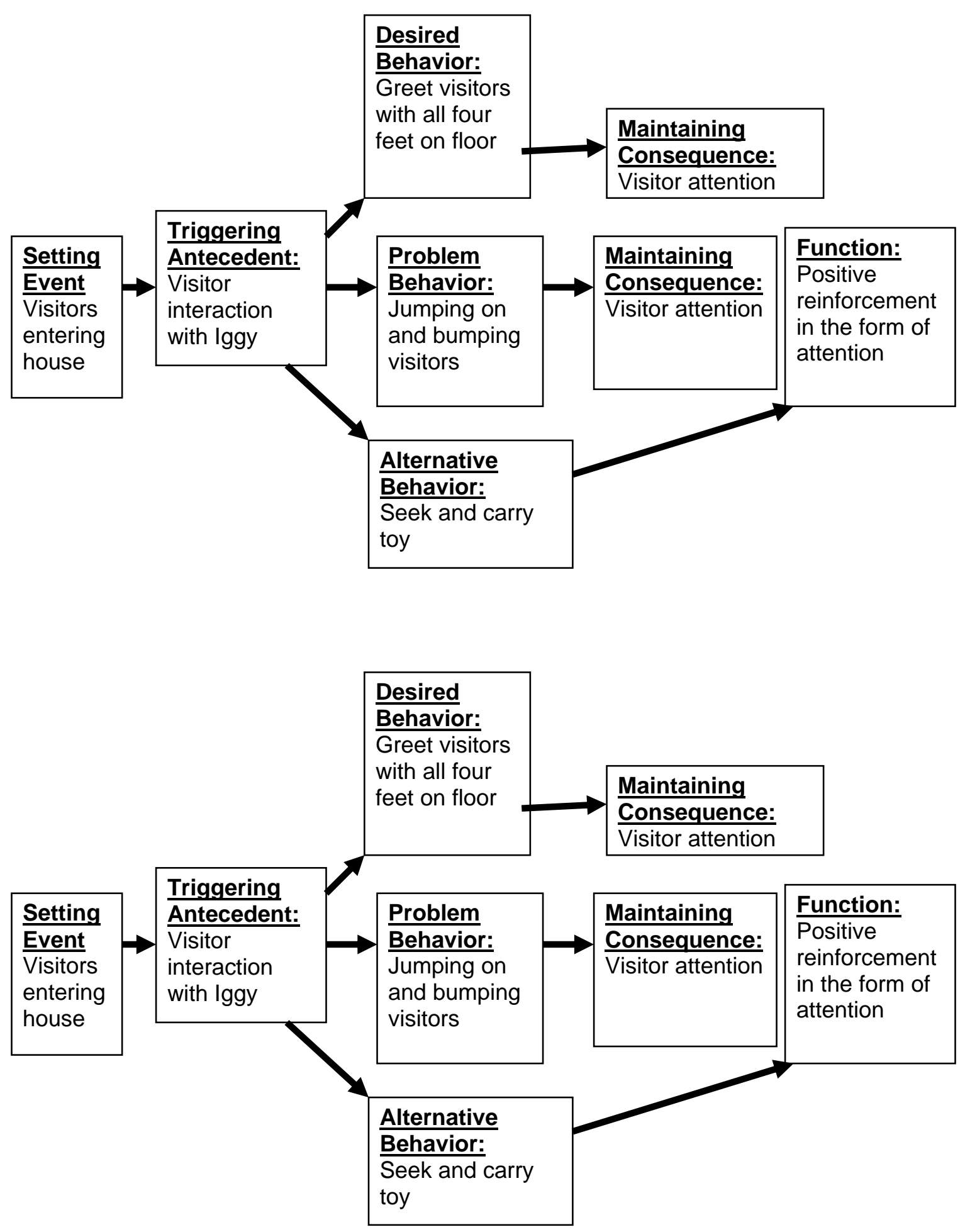

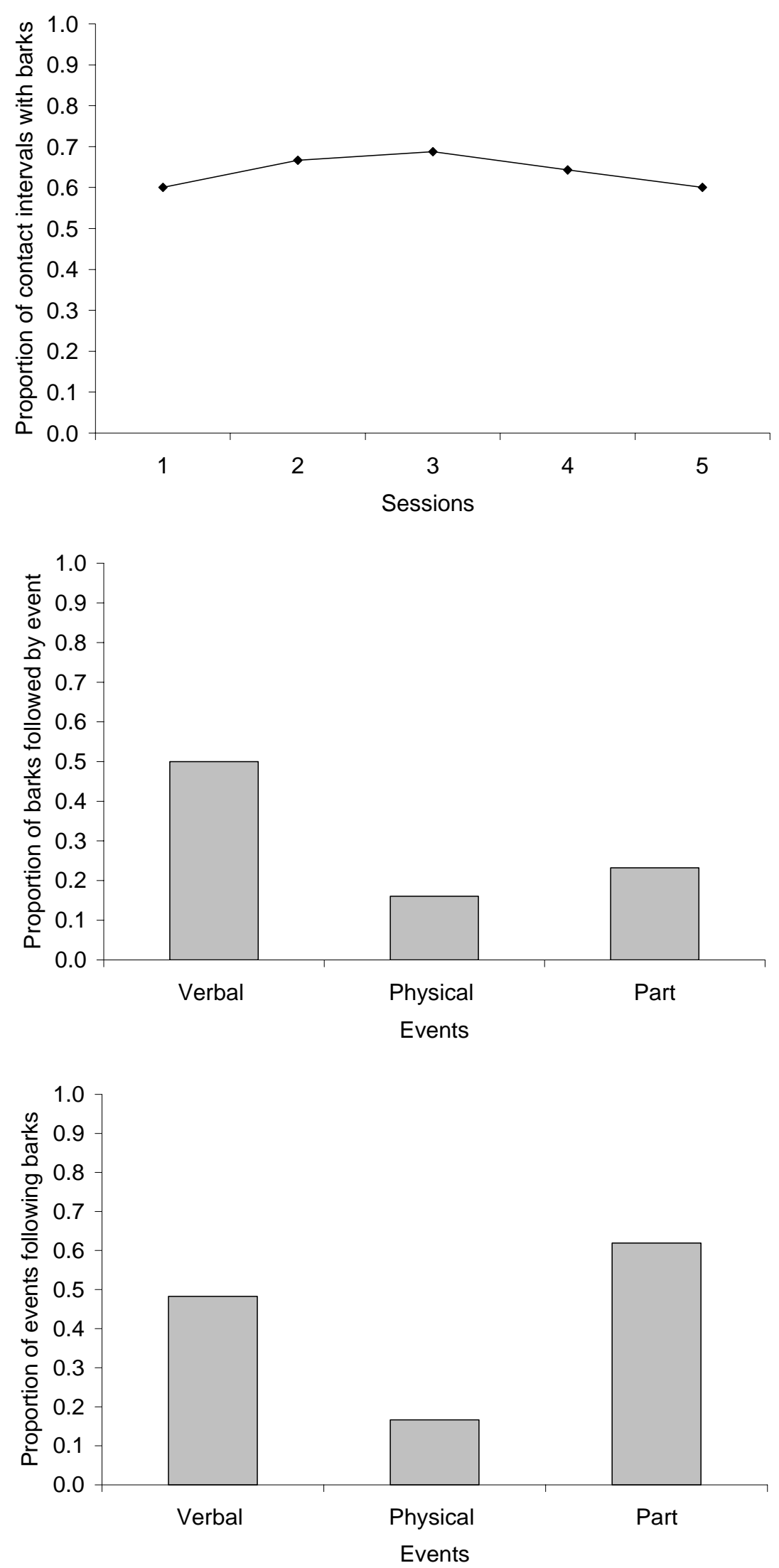

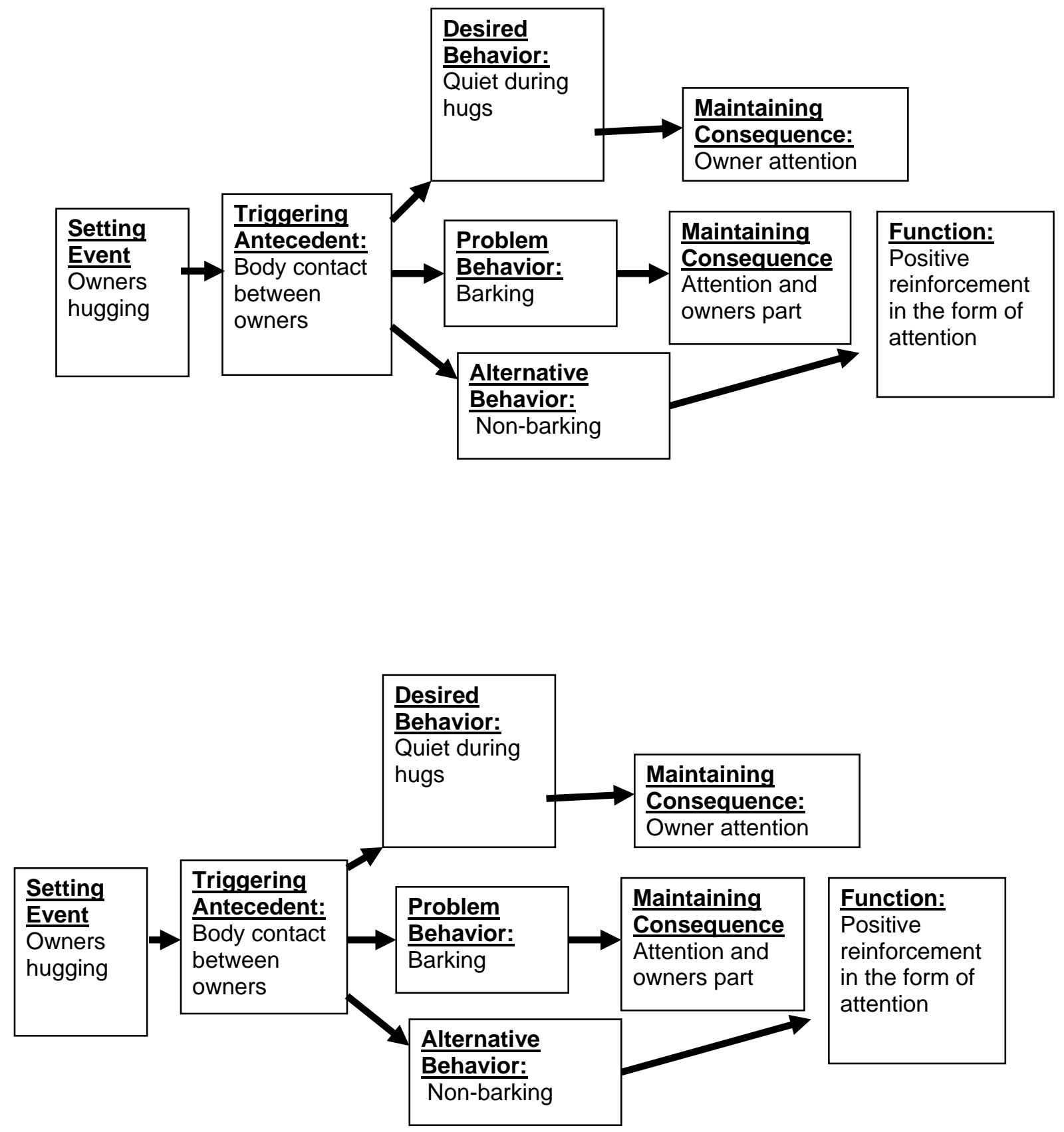


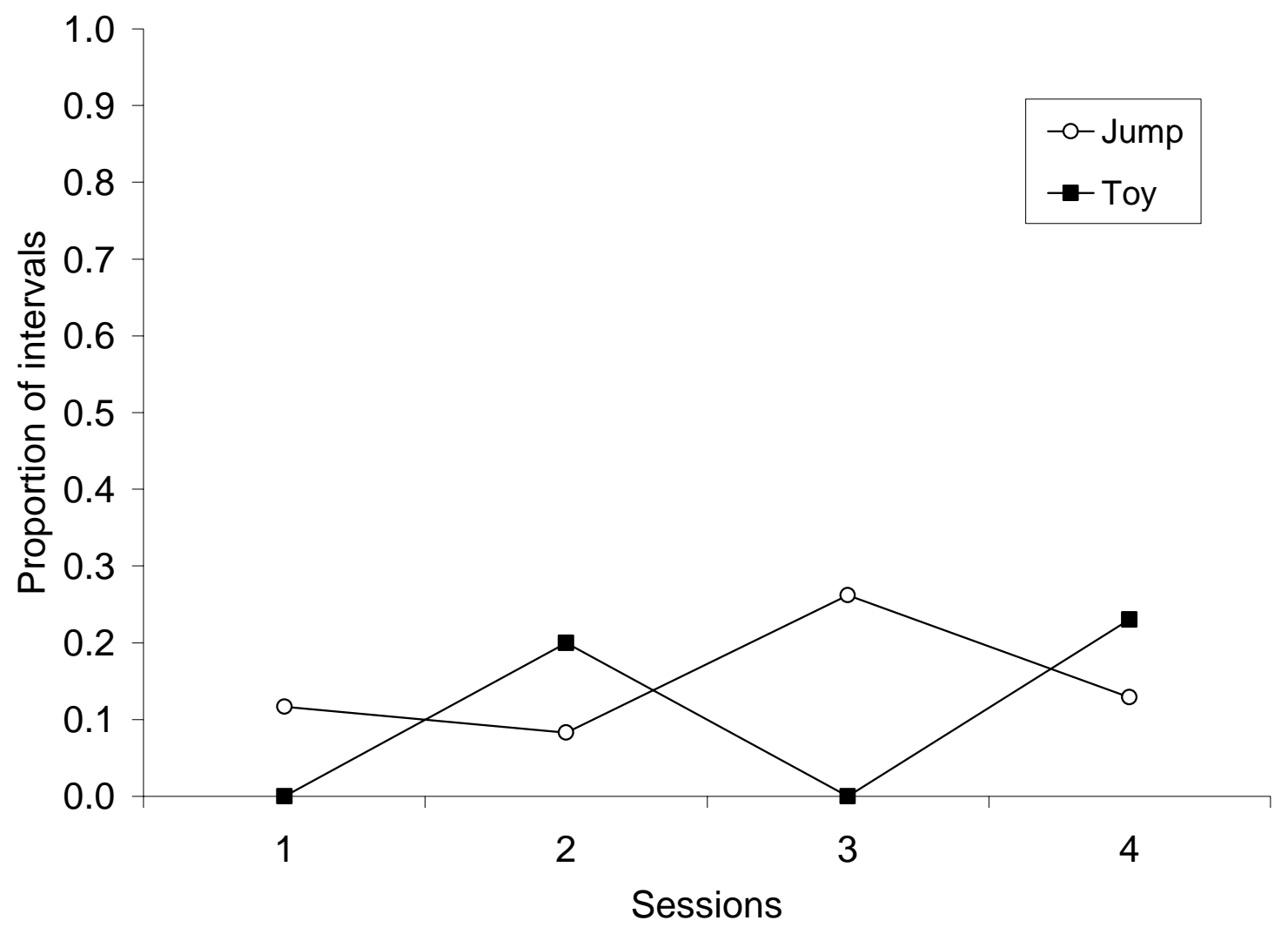


Assessing the Effectiveness 97
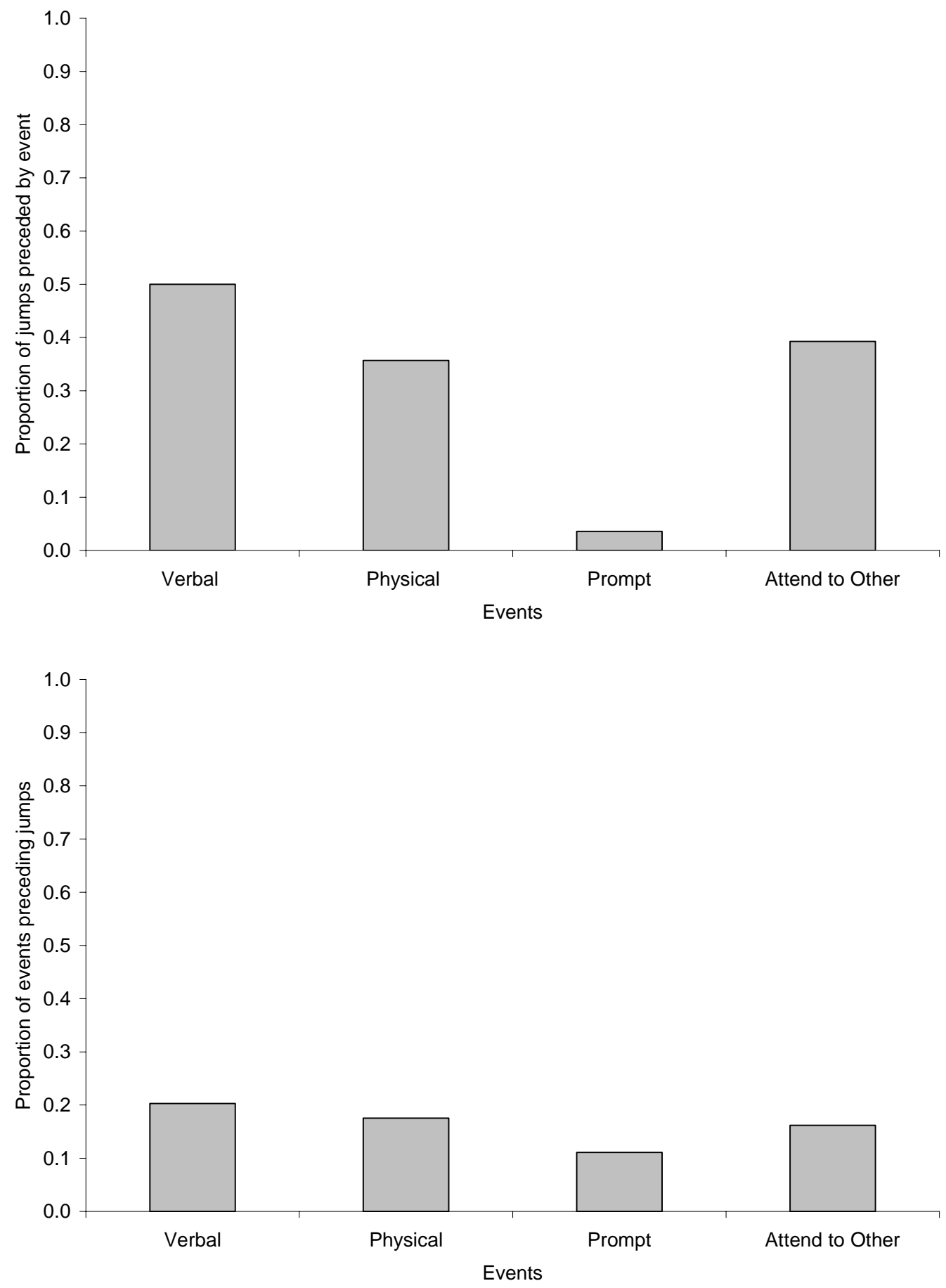
Assessing the Effectiveness 98
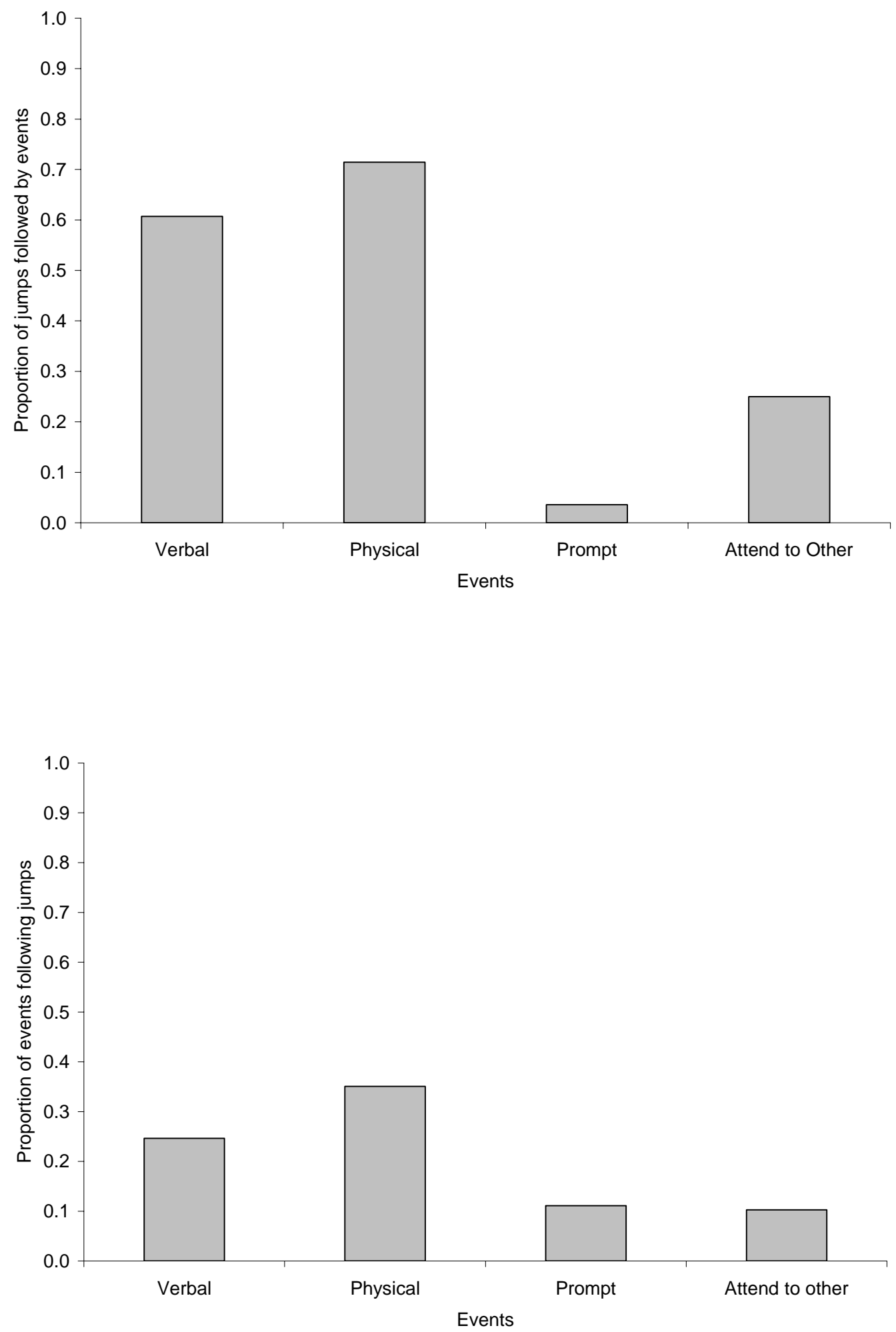

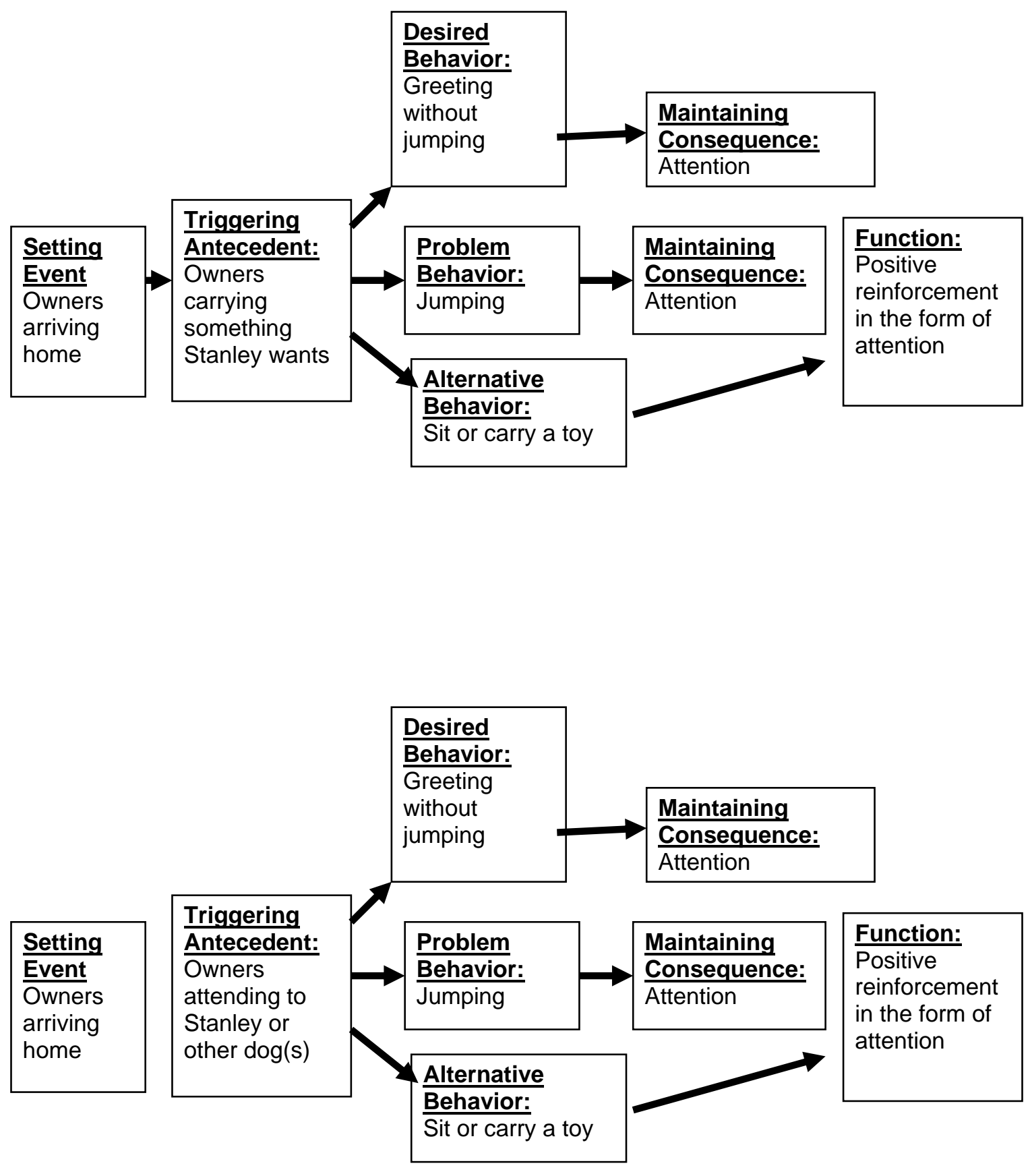


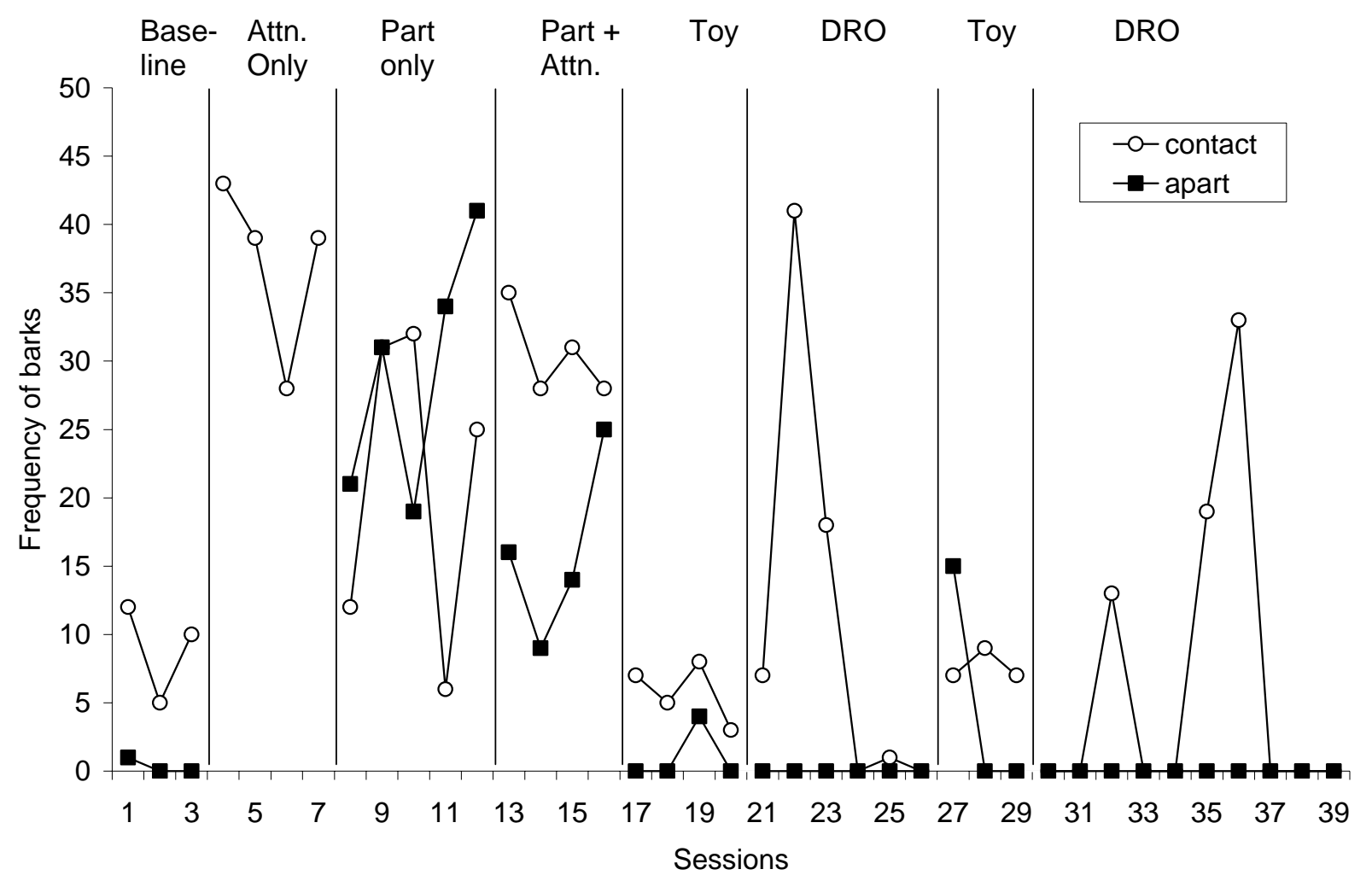




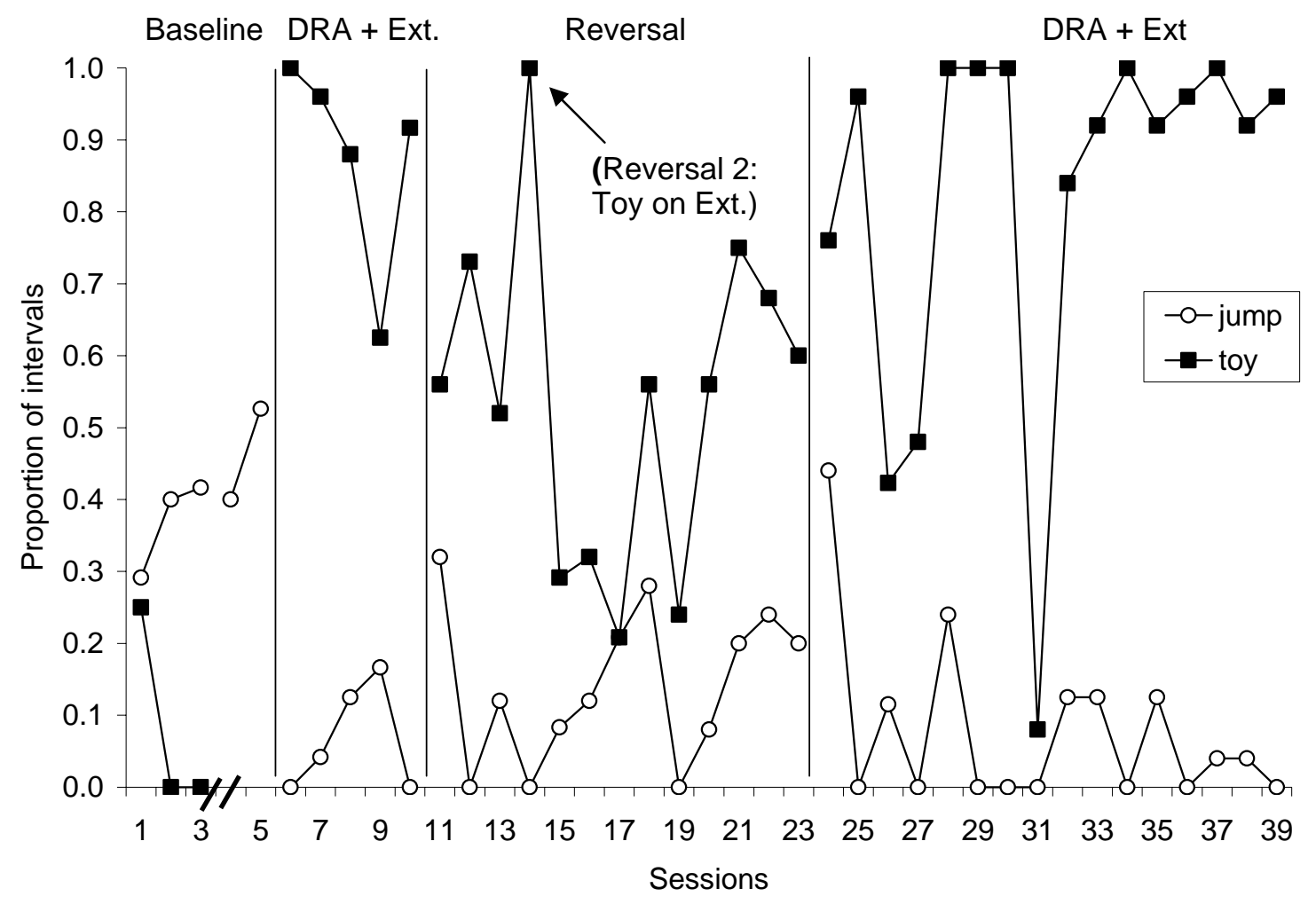



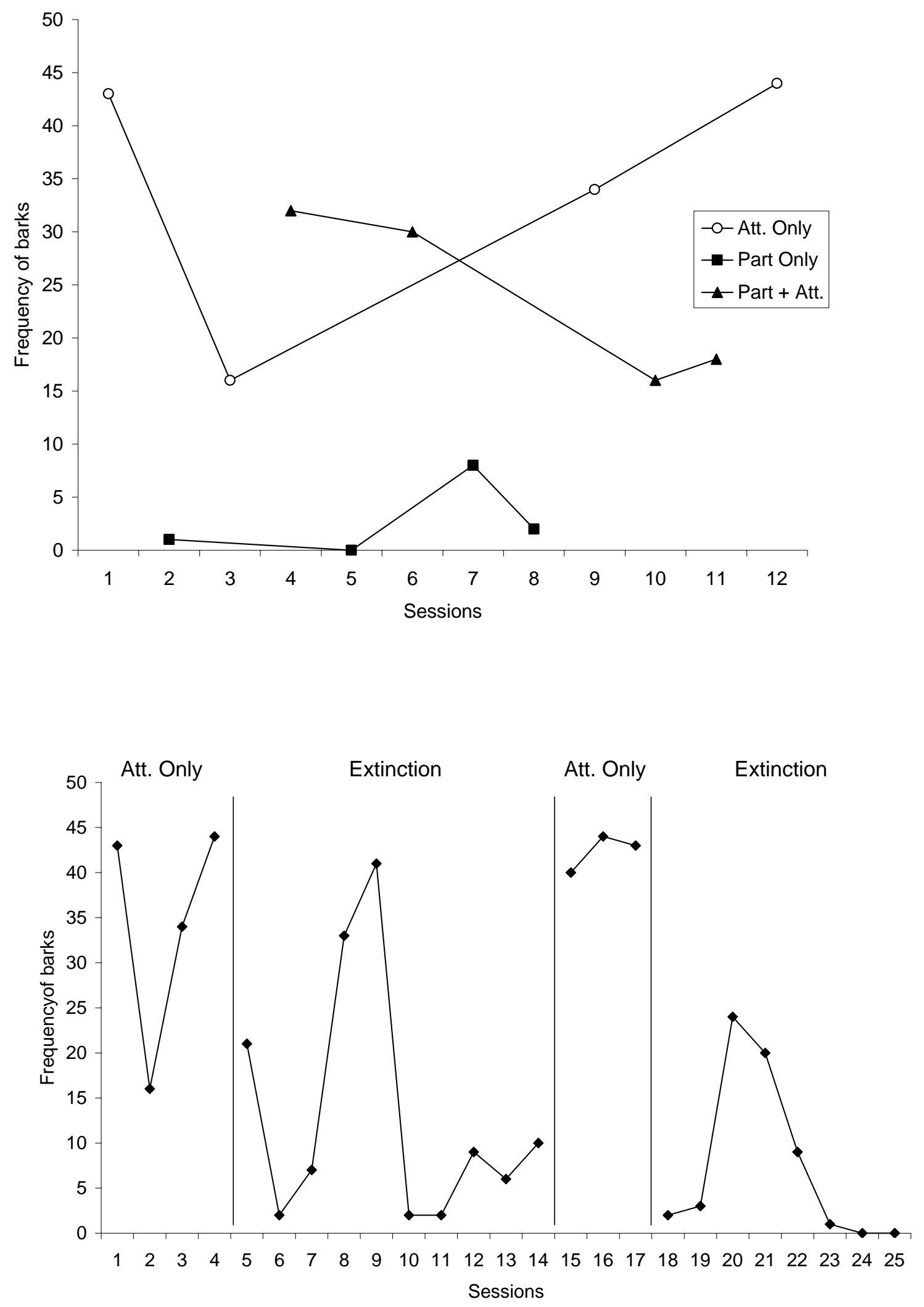
Assessing the Effectiveness 103

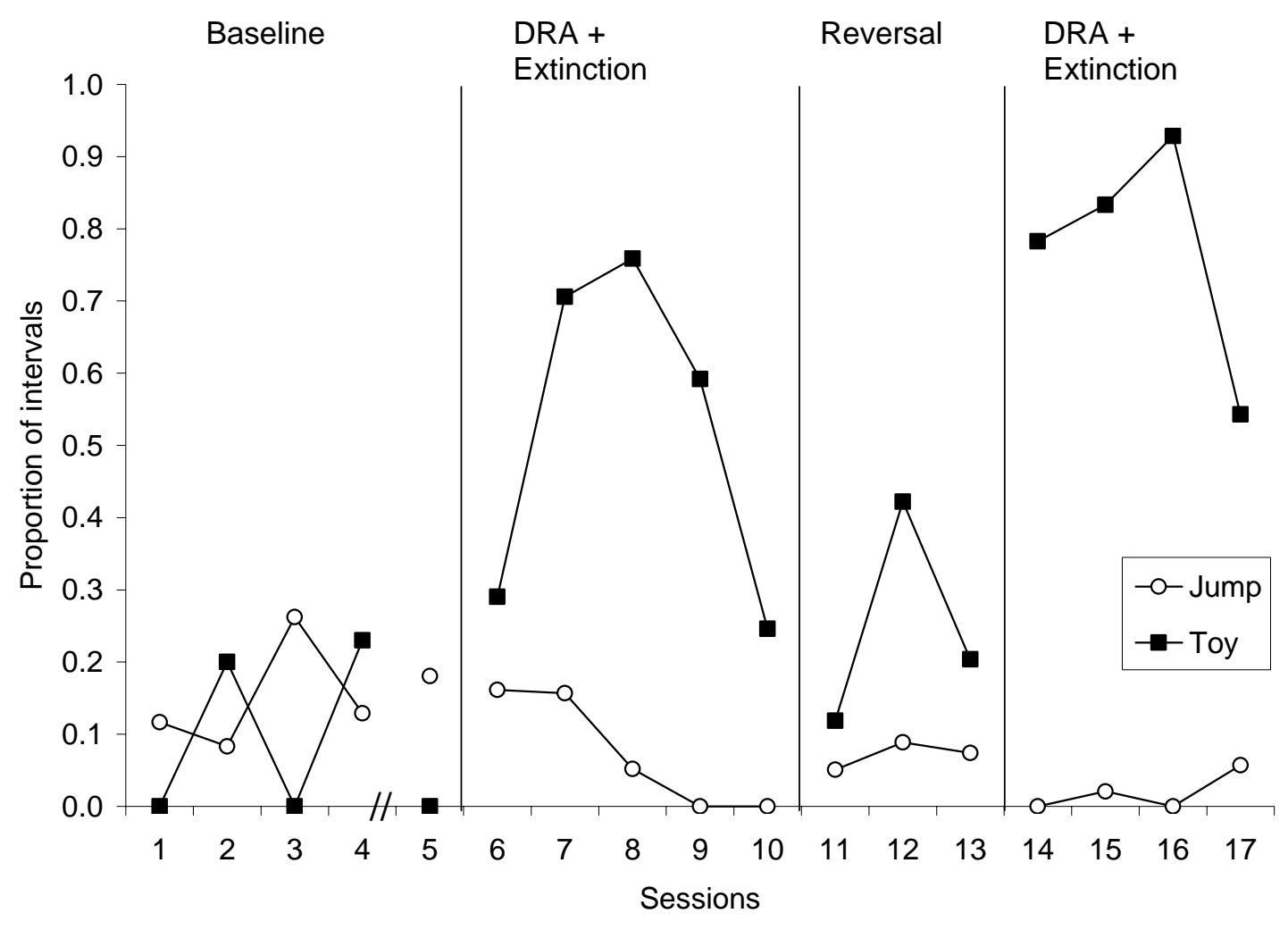

